Syracuse University

SURFACE

Theses - ALL

January 2017

\title{
Factors Associated with Parental Treatment Attitudes and Information-Seeking Behaviors for Childhood ADHD
}

Lea Elizabeth Taylor

Syracuse University

Follow this and additional works at: https://surface.syr.edu/thesis

Part of the Social and Behavioral Sciences Commons

\section{Recommended Citation}

Taylor, Lea Elizabeth, "Factors Associated with Parental Treatment Attitudes and Information-Seeking Behaviors for Childhood ADHD" (2017). Theses - ALL. 146.

https://surface.syr.edu/thesis/146

This Thesis is brought to you for free and open access by SURFACE. It has been accepted for inclusion in Theses ALL by an authorized administrator of SURFACE. For more information, please contact surface@syr.edu. 


\begin{abstract}
Background: Childhood ADHD is an impairing neurodevelopmental disorder with associated long-term negative outcomes in a variety of domains. Despite this, there is a significant delay to treatment and a low rate of lifetime treatment contact for individuals with ADHD. Barriers to child treatment include parental poor symptom recognition, attitudinal barriers, evaluative barriers, fear of stigma, and structural barriers. These barriers are important to consider in the context of the family system, as parents serve as gatekeepers to mental health treatment for their children. In addition, parents' perceptions of the quality and type of their children's symptoms may also inform their information-seeking behaviors and ultimately, treatment decisions. The current study aimed to examine (a) variables associated with treatment-seeking attitudes, (b) variables associated with information-seeking behaviors, and (c) the relationship between treatment-seeking attitudes and information-seeking behaviors in a non-treatment-seeking parent sample.
\end{abstract}

Method: Data from 169 non-treatment-seeking parents were analyzed. All parents participated in an online study that assessed their perceptions of their own children's symptoms, parenting selfefficacy, satisfaction with treatment providers for themselves and their child, knowledge about ADHD and treatment, symptom recognition, stigma towards ADHD, and treatment attitudes. Information-seeking behaviors were also measured.

Results: Linear and logistic regressions analyzed the association between parental factors and treatment attitudes and information-seeking behavior, as well as the association between attitudes and information-seeking behavior. In these non-treatment-seeking parents, attitudes towards ADHD treatment were significantly associated with ADHD knowledge and misconceptions, causal attributions and understanding of ADHD, parenting self-efficacy, ADHD stigma, ADHD knowledge, and satisfaction with past providers. No hypothesized factors were significantly associated with information-seeking behavior. Attitudes towards treatment and informationseeking behavior were also not significantly associated with each other.

Discussion: Parental knowledge and understanding of ADHD symptoms and treatment, low levels of ADHD stigma, and positive experiences with past medical providers for oneself and one's child were the best predictors of holding positive attitudes about ADHD treatment. Significant relations between these factors and treatment attitudes and information-seeking behavior did not emerge, however, highlighting the need for additional research on factors associated with treatment attitudes as well as continued study of how best to enhance treatment attitudes.

Key words: ADHD, stimulant, parents, treatment-seeking, treatment attitudes, barriers 
Factors Associated with Parental Treatment Attitudes and Information-Seeking Behaviors for Childhood ADHD

$$
\text { by }
$$

Lea E. Taylor

B.A., Skidmore College, 2015

\author{
Master's Thesis \\ Submitted in partial fulfillment of the requirements for the degree of \\ Master of Science in Clinical Psychology
}

Syracuse University

May 2017 
Copyright (C) Lea E. Taylor 2017

All Rights Reserved 


\section{Acknowledgements}

I would like to acknowledge and thank Dr. Antshel for his mentorship on my defense committee. I would also like to thank Dr. Felver, Dr. Woolf-King, and Dr. Ditre for taking the time to serve on my committee and provide feedback. Undergraduate RAs, Yealim Chung, Eric Moskowitz, Jessica Carvajal, Samantha Mozden, Jeffrey Albelo, and Arden Colonna-Mosley, provided valuable help in data coding and cleaning. I also thank the Syracuse University Psychology Department for funding this project in part. 
Table of Contents............................................ $\quad$ v.

List of Tables.................................................. vii.

List of Figures................................................. viii.

\section{Chapters}

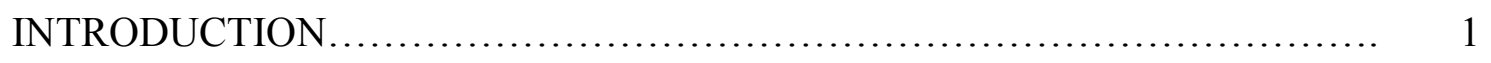

ADHD...................................................... 1

ADHD Treatment Decision-Making.............................. 8

Summary / Need for Current Study................................... 18

Hypotheses................................................... 22

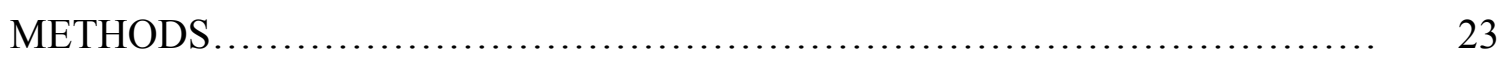

Participants...................................................... 23

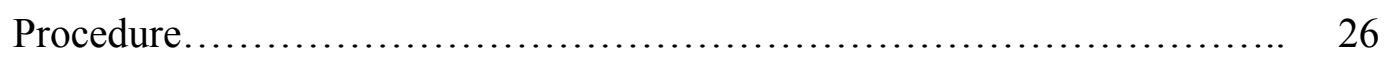

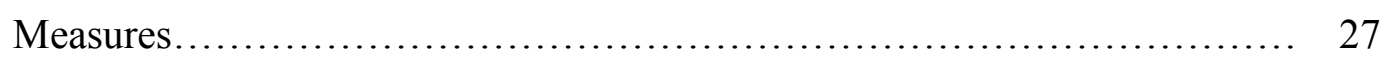

Preliminary Analyses.............................................. 34

Planned Analyses............................................... 37

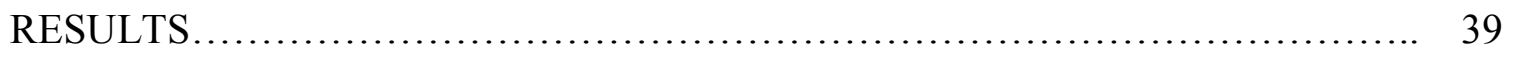

Hypotheses.................................................. 40

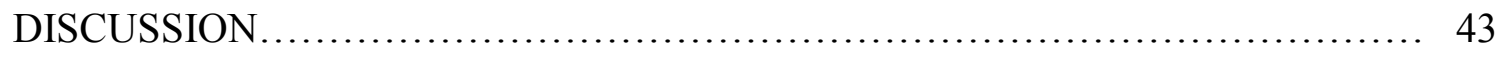

Hypotheses................................................. 44

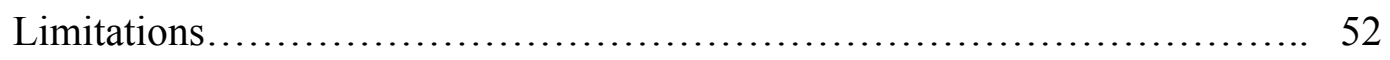


Directions for Future Research and Implications for Clinical Practice....... 56

Conclusions................................................... 60

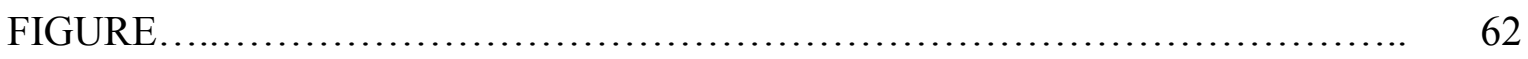

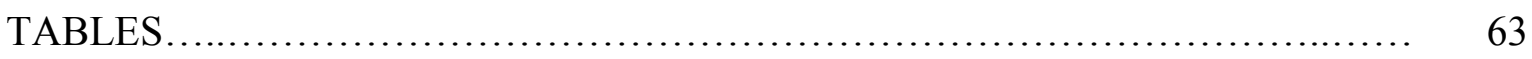

REFERENCES................................................... 76

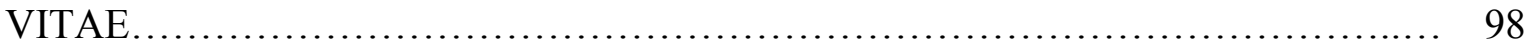




\section{List of Figures}

Figure

PAGE

1. Hypotheses and Data Analysis of the Current Study..................................... 62 


\section{List of Tables}

Table

PAGE

1. Demographic, Predictor, and Outcome Variables ................................. 63

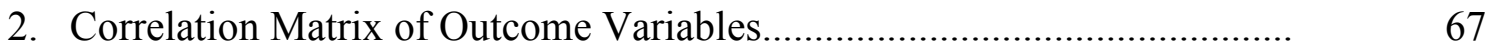

3. Component Loadings and Communalities ........................... 69

4. Results of Linear Regression.....................................................

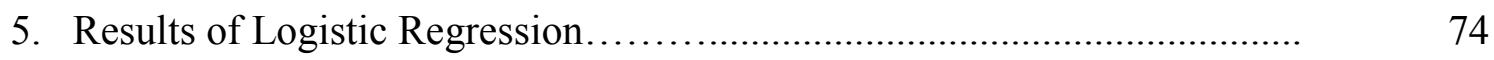

viii. 
Factors Associated with Parental Treatment Attitudes and Information-Seeking Behaviors for Childhood ADHD

\begin{abstract}
ADHD
ADHD background. The onset of many major mental health disorders, including attention deficit / hyperactivity disorder (ADHD), occurs during childhood and adolescence (Kessler et al., 2005b). The national comorbidity survey replication (NCS-R) study reported that half of all lifetime cases of psychiatric disorders occur before the age of 14, indicating that childhood represents an area of importance for research focusing on diagnosing and treatmentseeking behaviors (Kessler et al., 2005b). Specifically, childhood ADHD represents a clinically important area of study due to its high prevalence, as high as $11 \%$ in some epidemiological studies (Visser et al., 2014), the severity of functional impairment associated with ADHD (Molina et al., 2009), the high prevalence of psychiatric comorbidities (Biederman, Newcorn, \& Sprich, 1991; Jensen et al., 2007) and associated negative long-term consequences (Barkley, Fischer, Smallish, \& Fletcher, 2006; Biederman et al., 1998a). Furthermore, ADHD poses a significant economic burden on the United States; in 2000 the estimated cost was $\$ 31.6$ billion (Birnbaum et al., 2005). In short, ADHD is a prevalent, clinically significant disorder with a multitude of negative implications.
\end{abstract}

ADHD is characterized by inattention, hyperactivity, and/or impulsive symptoms that cause significant functional impairment (American Psychiatric Association, 2013). Several of these symptoms must be present before age 12 . There is great heterogeneity in ADHD due to the wide variety of possible symptom combinations that may lead to a diagnosis (Wåhlstedt, Thorell, \& Bohlin, 2009). ADHD symptoms are associated with significant impairment in diverse areas 
such as educational, motivational, social, psychomotor, and emotional functioning, among other areas (Schipper et al., 2015).

ADHD is the most commonly diagnosed and treated childhood psychiatric disorder (Akinbami, Liu, Pastor, \& Reuben, 2011; Spencer, Biederman, \& Mick, 2007). The National Health Interview Survey data revealed that the lifetime prevalence of children with ADHD increased 29\% from 1998 to 2009 (Akinbami et al., 2011). Despite the high prevalence rate, the causes and development of ADHD is still contended and controversial (Ford-Jones, 2015; Schwarz, 2013). Although there is substantial body of work to support the diagnosis and treatment of ADHD as a disorder (Barkley, 2002), some argue that the diagnosis of ADHD represents an over-pathologization of normal personality traits (e.g., Szasz, 2003).

Longitudinal persistence of ADHD. Previously thought to dissipate in adolescence, the persistence of ADHD into adulthood has been empirically supported (Wilens, Biederman, \& Spencer, 2002). In typically developing children, hyperactivity symptoms decline, although inattentive symptoms persist (Spencer et al., 2007). Children with ADHD are at risk for later school failure, emotional difficulties, dysfunctional peer relationships and legal difficulties as adolescents (Spencer et al., 2007). The developmental trajectories of children with ADHD are quite heterogeneous with $20 \%$ of children functioning poorly at a 4 -year follow-up, $20 \%$ functioning well, and 60\% functioning intermediately (Biederman, Mick, \& Faraone, 1998b; Spencer et al., 2007). However, not all children with ADHD will become adults with ADHD. The persistence of ADHD into adulthood is predicted by a variety of factors including symptom severity, maternal psychopathology, family size, psychiatric comorbidity and intelligence (Biederman et al., 1998b). ADHD is associated with significant psychiatric comorbidities such as oppositional defiant disorder (ODD), conduct disorder (CD), major depressive disorder (MDD), 
and anxiety disorders, and predicts substance-use disorders, later poor academic performance, psychological maladjustment, employment difficulties, immaturity and divorce (Spencer et al., 2007). Although ADHD is a condition that has the potential to cause significant long-term negative outcomes, there are a variety of evidence-based treatments that confer hope for parents and children with ADHD.

ADHD etiological theory. Current research supports a variety of theories regarding the etiology of ADHD (Barkley, 1997; Sonuga-Barke, 2002) and each theory likely describes a subset of individuals with ADHD. ADHD is multidimensional and the large etiological literature cites many likely pathways to ADHD (Scassellati, Bonvicini, Faraone, \& Gennarelli, 2012; von Rhein et al., 2015). For example, genetic transmission plays a significant role in the development of ADHD (Biederman \& Faraone, 2005). Heritability data from twin and adoption studies demonstrates that genetic factors account for approximately 76 to $80 \%$ of the etiology for ADHD (Biederman \& Faraone, 2002, 2005). Genome wide association studies have provided less consistent results with significant heterogeneity of genome regions for ADHD suggesting that it is unlikely that specific genome regions have large effects on the disorder globally (Biederman \& Faraone, 2005). Heterogeneous genomic sites may contribute to some of the heterogeneity in the disorder.

In addition, various neurotransmitters may be involved in the pathophysiology of ADHD. Individuals with ADHD may have a greater density of dopamine transporters (DAT) in their brain compared to those without ADHD (Dougherty et al., 1999). Effective pharmacological treatments for ADHD target the dopamine and norepinephrine systems, which similarly suggests that these systems are involved in the etiology of ADHD symptoms (Dougherty et al., 1999; 
Dresel et al., 2000). For example, methylphenidate decreases the number of available DAT, and this decrease correlates with a reduction of ADHD symptoms (Dresel et al., 2000).

In addition to biological theories, there are a variety of cognitive theories that attempt to explain ADHD. A review indicated that although theories of ADHD cite executive functioning deficits as central to ADHD, and that weaknesses in executive functioning are associated with ADHD, executive functioning deficits are not present in all children with ADHD (Lambek et al., 2011); nonetheless, at the group level, when compared to those without ADHD, executive functioning impairment is characteristic of the disorder (Killeen, Tannock, \& Sagvolden, 2012; Willcutt, Doyle, Nigg, Faraone, \& Pennington, 2005). Many cognitive theories of ADHD propose that ADHD is related to insufficient brain activation and/or dysfunctions in neurophysiology. These insufficient activation patterns affect executive (i.e., planning, monitoring, detection of errors, and error correction), computational mechanisms of attention (i.e., encoding, search, decision, and motor organization), and energetic (i.e., effort, arousal, and activation) functioning (Sergeant, 2005).

These cognitive, neurophysiological, and genetic factors likely account for much, but not all, of the risk for developing ADHD. There are likely complex interactions between underlying biological factors that interact with environmental variables to lead to ADHD. Prenatal exposure to nicotine and alcohol, low birth weight, low socioeconomic status (SES), parental psychopathology, comorbid disruptive behavior disorders in parents and offspring, and paternal criminality, may also be risk factors for ADHD (Biederman \& Faraone, 2002, 2005). Additionally, some theories suggest that ADHD arises from environmental toxins such as lead when combined with other underlying risk factors (Nigg, Nikolas, Knottnerus, Cavanagh, \& Friderici, 2010). However, ADHD occurs in similar rates in countries where these toxins are 
common and uncommon (Killeen et al., 2012). Despite the popularization of the idea that different diets (e.g., high sugar content foods) may cause ADHD, this theory has been widely debunked (Biederman \& Faraone, 2005). Finally, maladaptive reinforcement of impulsive, hyperactive, and inattentive behaviors through immediate gratification may help explain the maintenance of ADHD symptoms (Aase \& Sagvolden, 2005). Overall, although there may be important environmental triggers, these theories do not explain the etiology of ADHD alone. Likely, there are complex interactions between biopsychosocial factors that lead to the development of ADHD. The above theories are both informed by and guide the evidence-based treatments.

ADHD treatment. There are a variety of evidence-based pharmacological and nonpharmacological treatments for ADHD that vary in effectiveness, side effects, and perceived acceptability by children and their parents. Both the American Academy of Pediatrics (AAP) (Subcommittee on Attention-Deficit/Hyperactivity et al., 2011) and the American Academy of Child and Adolescent Psychiatry (AACAP) (Pliszka, 2007) recommend stimulant medication as a front-line intervention for children and adolescents with ADHD. Methylphenidate, amphetamine, and other stimulants mechanistically enhance the neurotransmission of dopamine and norepinephrine (Swanson \& Volkow, 2002). In addition to the stimulant medications, several non-stimulant medications are also FDA-approved for treating ADHD in children and adolescents. Guanfacine, atomoxetine and clonidine are all non-stimulant medications that are used in pediatric ADHD management. Largely based upon the weaker effect sizes associated with non-stimulants ( 0.95 for stimulants and 0.62 for non-stimulants) (Faraone, 2003), both $A A P$ and $A A C A P$ recommend that providers prescribe a stimulant before considering non-stimulants (Pliszka, 2007; Subcommittee on Attention-Deficit/Hyperactivity et al., 2011). 
In popular culture and the media, stimulants are viewed as controversial due to the perceived possibility of tics, affect flattening, increased risk of substance abuse/misuse, and stunted growth, none of which have been empirically confirmed (Faraone, 2003). For example, despite fears of ADHD increasing the likelihood of a future substance use disorder, a metaanalysis of longitudinal research on children with ADHD indicated that pharmacological treatments may actually reduce the risk for a substance-use disorder by $50 \%$ (Wilens, Faraone, Biederman, \& Gunawardene, 2003). Furthermore, the development of long-acting stimulants has increased the ease of use for stimulants, with similar effectiveness and side-effects as the immediate release formulations, as well as decreased the potential for misuse/abuse (Biederman \& Faraone, 2005). However, despite the effectiveness of stimulants, and for multitude of reasons, parents may opt to not engage in pharmacological treatments in favor of nonpharmacological treatments for their children.

A meta-analysis of nonpharmacological treatments for ADHD indicated that some nonpharmacological treatments may be efficacious (Hodgson, Hutchinson, \& Denson, 2014). Specifically, behavior modification (i.e., the use of reinforcement and punishment to shape behavior) and neurofeedback (i.e., training in controlling and decreasing theta wave activity and increasing beta wave activity as a means to enhance attention and concentration) were both supported as evidence-based nonpharmacological treatments for ADHD symptoms (Hodgson et al., 2014). Another meta-analysis indicated some empirical support for fatty acid supplementation and dietary restrictions for treating ADHD symptoms (Sonuga-Barke et al., 2013). Support for other nonpharmacological treatments (e.g., behavioral parent training, working memory training) for targeting ADHD symptoms (not associated functional 
impairments) is more mixed (Hoath \& Sanders, 2002; Hodgson et al., 2014; Klingberg et al., 2005).

Although the Multimodal Treatment Algorithm (MTA) study indicated that stimulant medication is the most effective treatment for ADHD symptoms, adding behavioral treatments such as behavior modification may be of benefit for children who have ADHD and other comorbid conditions (Jensen et al., 2007). Despite the encouraging nonpharmacological data reviewed above, pharmacological treatment remains the most effective in treating core ADHD symptoms whereas nonpharmacological treatments may be useful as supplementary interventions for targeting functional impairments (Faraone, 2003). Thus, pharmacological treatments are generally considered to be a first-line treatment option for those with ADHD (Pliszka, 2007; Subcommittee on Attention-Deficit/Hyperactivity et al., 2011).

Impact of ADHD treatment on outcomes. In a systematic review of long-term outcomes in ADHD, Shaw and colleagues (2012) identified nine major outcome domains that have been studied: 1) drug abuse/addictive behavior, 2) academic functioning (e.g., grade point average), 3) antisocial behavior, 4) social functioning, 5) occupational functioning, 6) selfesteem (e.g., self-perception, suicidal ideation), 7) driving (e.g., automobile accidents), 8) service use (e.g., justice system, emergency health care), and 9) obesity. Individuals with untreated ADHD demonstrated poorer outcomes compared to non-ADHD participants in $74 \%$ of the outcome domains. Treated ADHD was associated with greater improvement compared to no treatment, improvement within-subjects as compared to baselines, and stabilization compared to baselines (i.e., no deterioration as seen in untreated ADHD). In addition, several studies included in Shaw and colleagues' (2012) review found that over time (two to nine years) outcomes such as academic performance of participants with untreated ADHD decreased (Powers, Marks, 
Miller, Newcorn, \& Halperin, 2008; Schultz, Evans, \& Serpell, 2009) and tobacco use increased (Whalen, Jamner, Henker, Gehricke, \& King, 2003). Conversely, social outcomes in the treated ADHD group improved less robustly than other outcomes over eight years (Shaw et al., 2012). Overall though, Shaw and colleagues' (2012) systematic review demonstrated that treatment of ADHD improves long-term outcomes, though typically not to the point of normalization of functioning (Ramos-Quiroga \& Casas, 2011).

\section{ADHD Treatment Decision-Making}

ADHD is a persistent and impairing disorder with negative long-term consequences. Evidence-based treatment during childhood and adolescence may decrease the impact of these consequences (Goksoyr \& Nottestad, 2008; Shaw et al., 2012; Wilens et al., 2002). Despite the effectiveness of evidence-based treatments and the long-term negative impact of untreated ADHD, the NCS-R revealed that only $51.8 \%$ of people who meet criteria for ADHD will ever make treatment contact (Wang et al., 2005). Data from the National Epidemiologic Survey on Alcohol and Related Conditions reported a similar predicted treatment rate, 55\% (Dakwar et al., 2014). Additionally, the median delay from symptom onset to treatment for ADHD is estimated at 10.5 to 28 years with younger cohorts at the shorter end of the delay (Dakwar et al., 2014). Currently there is insufficient work fully explaining why only half of those with ADHD will ever be treated as well as why the significant delay to treatment that exists in ADHD.

Parents may be unsure of when or where to seek treatment for their child (Bussing, Zima, Gary, \& Garvan, 2003). Likewise, over two thirds of parents with a child who meets criteria for ADHD do not see the need for professional treatment (Bussing et al., 2003). Children with more severe symptoms, males, Caucasians and parents who have social support are more likely to attempt to access treatment (Bussing et al., 2015; Bussing et al., 2003). Clearly, increasing access 
to and engagement in evidence-based treatments for ADHD is a public health issue; services for ADHD should not be limited to Caucasian boys whose parents have high levels of social support; further investigation is needed.

There are likely numerous and varied causes for the long delay to treatment and low rates of lifetime treatment engagement. Evidence from NCS-R indicates that the inability to recognize symptoms of a mental health disorder as well as attitudinal and evaluative barriers (e.g., low perceived credibility for treatments and presence of stigma respectively) are as significant or more significant than structural barriers (e.g., cost, transportation, etc.) in delaying or ceasing treatment (Mojtabai et al., 2011). Although structural barriers are significant, attitudinal and evaluative barriers are more important in predicting treatment initiation and continuation (Mojtabai et al., 2011). Understanding parental attitudes about ADHD treatment and how these attitudinal and evaluative barriers influence decision-making remains a topic that is less well understood.

Parental symptom recognition and treatment decision-making. Parental recognition of symptoms or behavioral problems in their children is a strong predictor of accessing all types of services (Sayal, Goodman, \& Ford, 2006). Nevertheless, although parents may be able to recognize the presence of ADHD symptoms, few access treatment for their children (Sayal et al., 2006). Although general practitioner failure to recognize symptoms or behavioral problems may be a significant barrier to accessing evidence-based treatment, parents often characterize their children's symptoms as behavioral, motivational or academic, rather than as inattention, and may not report it to their children's treatment providers (Sayal et al., 2006). Not recognizing ADHD symptoms or attributing ADHD symptoms to an external cause may both lead to fewer parents accessing treatment for their children. 
Parents play an additional role as gatekeepers to treatment and may elect to accept or deny access to evidence-based treatments for their children. Parents not only struggle in the decision to consent to a medication trial, but often revisit their decision (Brinkman et al., 2009). Parents report fears of the long-term negative effects of stimulants, even if their child has a positive response to the medication. Furthermore, parents report trial-stopping their children's medication without approval from the prescribing doctor. Clearly, some parents are ambivalent about employing an evidence-based intervention for their children with ADHD, due to their concerns (Brinkman et al., 2009).

Impact of stigma on treatment decision-making. Results from the National Stigma Study — Children (NSS-C) suggests that stigma may also play a role (Pescosolido, Fettes, Martin, Monahan, \& McLeod, 2007; Pescosolido et al., 2008). NSS-C data indicated that the general public perceives children with ADHD to be more dangerous to themselves and others compared to children with asthma or "daily troubles" (Pescosolido et al., 2007). In addition, most people are unable to correctly identify symptoms of ADHD, and even when they do, they are unlikely to identify ADHD as a neurodevelopmental or mental health disorder, reflecting public perceptions that ADHD may not truly exist or be as severe as other mental health disorders (Pescosolido et al., 2007; Pescosolido et al., 2008). Results from the NSS-C also indicated that the general public places more blame and responsibility on parents of children with ADHD for their child's ADHD compared to parents of children with depression and asthma (Mukolo \& Heflinger, 2011).

Parents of children with a mental health disorder may experience public or social stigma (Ahmed, Borst, Wei, \& Aslani, 2013). Fear of stigma is the most commonly cited reason for not accessing mental health treatment (Gulliver, Griffiths, \& Christensen, 2010). These concerns also exist for parents of a child with ADHD specifically (e.g., others questioning the existence of 
ADHD, blaming the parent for the child's misbehavior, concerns how others may view their electing to have their child on medication) (Bussing et al., 2012). The majority of parents of a child with ADHD (77\%) report experiencing stigma, 44\% report concern about how society might label their child, and $40 \%$ feel isolation and rejection because of their child's ADHD diagnosis (DosReis, Barksdale, Sherman, Maloney, \& Charach, 2010). Parents also report concerns about how diagnosis and treatment may affect their child's future (e.g., low selfesteem, decreased future success) (DosReis et al., 2010). Many parents of children with ADHD report that they experience stigma about their parenting practices from both family and the public (Ahmed et al., 2013). Likewise, mothers of children with ADHD expect parents of children without ADHD to have more negative views of children with ADHD (e.g., not being as bright as other children) even when the other parents do not endorse this view (Norvilitis, Scime, \& Lee, 2002). Fear of stigma is not only a barrier to accessing treatment, but is also a contributing factor to parents ceasing evidence-based pharmacological treatment for their children (Ahmed et al., 2013; Kazdin, Holland, \& Crowley, 1997).

Parental fears of stigma towards themselves or their own children reduce the likelihood of accessing ADHD assessment and treatment services. However, although the public stigmatizes children with symptoms of ADHD more than children without ADHD symptoms, adding a diagnostic label is associated with only marginally higher rates of stigma (Ohan, Visser, Moss, \& Allen, 2013). Thus, ADHD symptoms may be more stigmatizing than the label, "ADHD". It may be beneficial to use this information when developing informational programs that aim to understand and increase treatment-seeking. For example, if parents understand that symptoms drive stigma more strongly than a diagnostic label, these parents may be more likely to seek treatment for their child. Overall, understanding what motivates parents to seek evidence- 
based treatment for their children should inform how the health professional fields interface with parents.

Parental knowledge of and stigma towards ADHD treatment. A parent's decision to engage in different types of treatment, or treatment at all, for their children once they have a diagnosis of ADHD, is related to numerous parental cognitive factors. Parents often make these decisions in times of stress without having taken time to become better informed of their options. For example, one study of public attitudes towards ADHD and ADHD treatment reported that $78.3 \%$ of participants believe that too many children with a diagnosis of ADHD do not really have ADHD (e.g., are misdiagnosed) (Partridge, Lucke, \& Hall, 2014). In addition, the public endorses the use of medication as less acceptable for ADHD than medication treatment for depression (Partridge, Lucke, \& Hall, 2012; Partridge et al., 2014). These public perceptions are important to consider when examining the context within which parents make treatment decisions as these public views negatively affect ADHD medication treatment attitudes (Partridge et al., 2014).

A portion of the negative attitudes about ADHD and associated evidenced-based treatments may be related to misconceptions and lack of knowledge about evidence-based interventions. In general, people with higher levels of educational attainment are more likely to endorse medication as a viable treatment for both ADHD and depression (Partridge et al., 2012). Higher education levels may be associated with increased informational exposure and better understanding of medication as well as ADHD in general. Moreover, higher levels of misconceptions about ADHD treatment (e.g., taking stimulant medications in childhood leads to recreational drug abuse in the teenage years) and lower levels of knowledge about ADHD and evidence-based treatments are related to lower perceived acceptability of ADHD medications 
(Sciutto, 2015). Likewise, parental knowledge about ADHD is positively associated with medication acceptability, parental knowledge about ADHD is not related to counseling acceptability (Bennet, Power, Rostain, \& Carr, 1996). Lack of knowledge about these treatments may lead a parent to endorse counseling over medication. Yet after learning more about medication treatment, these same parents might become more accepting of medication based on its better effectiveness and outcomes. Taken together, these results indicate that parental educational attainment and exposure to information about ADHD predict attitudes about ADHD medications.

Consistent with these results, one study that examined the acceptability of methylphenidate and behavior modification for ADHD, found that parents of both children with and without ADHD viewed behavior modification as the most acceptable option, combined treatment as the second most acceptable, and medication as the least acceptable for treatment of their children (Liu, Robin, Brenner, \& Eastman, 1991). However, after personal experiences with these interventions, the acceptability of combined treatment and medication significantly increased. This increase in acceptability was associated with an increase in knowledge, but not with an actual improvement in symptoms. Stroh, Frankenberger, Wood, and Pahl (2008) reported similar results in that parents of children with ADHD rated the effects of medication more positively than parents of children without ADHD. In addition, parents of children with ADHD rated the side effects of ADHD medications as less severe than parents of children without ADHD. These results suggest that increased understanding and personal positive experiences medication may lead to higher parental acceptability ratings. Therefore, it may be important to educate parents on both the benefits of medication and the risks of not utilizing medication, to 
help parents understand why medication, even with possible side effects, may represent an important treatment consideration.

Parental attitudes are also important due to their effect on actual treatment-seeking behaviors and subsequent treatment adherence. Positive parental attitudes towards the benefits of stimulant medications for ADHD predict later adherence to medication and perceived medication acceptability (Hebert, Polotskaia, Joober, \& Grizenk, 2013). Parents are less willing to engage in both psychosocial and pharmacological treatments for their children if they do not feel

knowledgeable about or endorse the acceptability of these treatments (Bussing et al., 2012). Unsurprisingly, willingness to engage in treatment for their children is positively related to parents' views on the acceptability and helpfulness of treatment (Bussing et al., 2012). These results further support the importance of parental knowledge in predicting treatment-seeking and adherence behaviors.

Parent self-efficacy and treatment decision-making. Parents' attitudes about themselves in their parent role, termed parenting self-efficacy, is positively associated with perceptions of effectiveness for behavioral treatments for ADHD (Jiang, Gurm, \& Johnston, 2014). This may be due to the need for a high level of parental engagement in ADHD behavioral treatments (e.g., consistently apply reinforcement schedules). If parents feel more equipped to participate effectively in their child's treatment, they may be more hopeful about the possible effectiveness of behavioral treatments that have increased parental demands.

Another study examined mothers of children with ADHDs' ratings of acceptability and effectiveness of psychosocial and stimulant medications for their own children and for children described in case vignettes (Johnston, Hommersen, \& Seipp, 2008). Mothers rated behavioral training as more acceptable than medication and behavioral training and medications as equally 
effective for a vignette child described as having ADHD. However, these same mothers rated medication as more effective than behavioral training for their own children, despite viewing behavioral interventions as more acceptable than medication. These findings suggest the presence of possible dissonance between views of acceptability and views of effectiveness of treatments. In addition, mothers' previous experiences with behavioral interventions were positively associated with ratings of effectiveness of behavioral interventions. This is consistent with Jiang et al.'s (2014) findings and suggests that perceptions of ability to successfully participate in behavioral interventions are related to both preference for, and ratings of effectiveness for, these treatments.

A third study examining parenting self-efficacy supported these conclusions. Johnston, Mah, and Regambal (2010) found that mothers with higher parenting self-efficacy believed that behavioral intervention was more likely to be effective. These beliefs predicted future positive treatment experiences. These data again implicate parenting self-efficacy as predictive of experiences and success of behavioral treatments and highlight the need to understand the specific variables in a family that may inform treatment success.

Child impairment is positively associated with mothers' ratings of the acceptability and effectiveness of combined treatment for a hypothetical child with ADHD (Jiang et al., 2014). Furthermore, when mothers viewed their own child's ADHD symptoms as more pervasive and within their child's control, they rated behavioral treatment as more acceptable. Parents actual experiences and successes when implementing these techniques, however, were unrelated to their perceptions of their child's symptoms (Johnston et al., 2010). Moreover, parents' perception of actual symptoms may affect what types of treatment they endorse. For example, parents' endorsements of their children's externalizing symptoms are related to acceptability of 
counseling therapy, but not medication use (Bennet et al., 1996). Parents who perceive their child as more oppositional and aggressive are more likely to pursue counseling, but not medication, as compared to parents who do not perceive their child's symptoms to be externalizing in nature. These findings indicate that parental perceptions of child symptoms may influence and increase treatment-seeking, but this effect is not consistent for all treatment types.

In addition to parent attitudes towards, and knowledge of, ADHD treatments, relationships with providers have also been demonstrated to be a significant predictor of treatment decision making for parents of children with ADHD.

The patient-doctor relationship. Children's access to treatment is complicated to the extent that they are developing within an bioecological (also referred to as ecological or socialecological) model comprised of microsystems (i.e., immediate environments such as school and family), mesosystems (i.e., links and relations between microsystems), exosystems (i.e., links between microsystems and outside environments such as the link between home and the parents' workplaces), macrosystems (i.e., patterns of various systems and cultures surrounding the child), and chronosystems (i.e., change over time in the various ecosystems of the child) (Bronfenbrenner, 1994; Tudge, Mokrova, Hatfield, \& Karnik, 2009).

Broadly, the bioecological model can be applied to this treatment-seeking paradigm. As highlighted, parents represent a critical component of a child's bioecological system, but they are not the only influential component of treatment access. Part of both parents' and children's bioecological system is the treatment provider. Given that three quarters of children and adolescents with psychiatric disorders are treated by primary care physicians (Martini et al., 2012), primary care physicians also represent gatekeepers to evidence-based treatments. Pediatric primary care physicians act as facilitators of knowledge about ADHD symptom 
recognition and knowledge / access to evidence-based treatment (Stiffman, Pescosolido, \& Cabassa, 2004).

One critical relationship in the child's exosystem that can affect parents' treatment attitudes and knowledge is the relationship between past medical providers and parents (Coletti et al., 2012; Ha \& Longnecker, 2010; Kraetschmer, Sharpe, Urowitz, \& Deber, 2004; Vermeire, Hearnshaw, Van Royen, \& Denekens, 2001). Parents of children with ADHD prefer treatment providers who are diagnostically expert, provide ample and varied psychoeducation, and explain ADHD using a chronic illness metaphor (Coletti et al., 2012), consistent with research in the general health field that patients want doctors who are both diagnostically competent and can communicate effectively (Ha \& Longnecker, 2010). Further, more concern about physician communication is raised than concerns about clinical competency (Ha \& Longnecker, 2010).

There are a variety of downstream effects from the patient-doctor relationship, such as reinforcing patient self-confidence, motivation, and hopefulness regarding treatment outcomes (Ha \& Longnecker, 2010). In addition, patients prefer shared decision-making with their doctors, and those who engage in shared decision-making have high levels of trust in their doctors (Kraetschmer et al., 2004). Active shared decision-making and high quality patient-doctor relationship are associated with adherence to medication (Vermeire et al., 2001). Thus, patientdoctor relationships have the potential to affect decisions that parents choose to make regarding their child's treatment.

Parental, especially maternal, psychiatric disorders are a risk factor for ADHD (Biederman, Faraone, \& Monuteaux, 2002; Biederman et al., 1995). This variable, however, has not been studied towards predicting treatment-seeking for their child. However, personal experiences and success with ADHD medication increases positive ratings of future medication 
treatment (Liu et al., 1991). Thus, examining how a parent's relationship with their own provider may might treatment decision making for their child likely represents a novel way to consider parental treatment decision making. The current study aims to investigate this topic.

\section{Summary / Need for Current Study}

Childhood ADHD is characterized by high prevalence, functional impairment, likelihood of psychiatric comorbidities and negative long-term consequences, a heterogeneous etiology, and a significant economic burden on the health care system rendering it a topic of significant public health import (Akinbami et al., 2011; Biederman \& Faraone, 2002, 2005; Birnbaum et al., 2005; R.C. Kessler et al., 2005b; Killeen et al., 2012; Lahey et al., 1994; Schipper et al., 2015). However, despite (a) the considerable public health problem represented by ADHD, (b) the availability and evidence base for effective treatments (e.g., stimulant medications) (Faraone, 2003), and (c) negative long-term impacts of untreated ADHD (Shaw et al., 2012), there is still a significant delay to treatment as well as low rate of lifetime treatment contact in the ADHD population (Dakwar et al., 2014; Wang et al., 2005).

The factors that influence the (lack of) treatment-seeking are copious and diverse. Poor symptom recognition, attitudinal barriers, and evaluative barriers are just as, or more significant barriers to treatment than structural barriers (Mojtabai et al., 2011). The general public does not label ADHD symptoms as characteristic of a clinical disorder (Bussing et al., 2003; Pescosolido et al., 2007). Parents of children with ADHD may fear public stigma about themselves or their children as well as harbor personal stigma about ADHD and its evidence-based treatments (Ahmed et al., 2013; Bussing et al., 2012; DosReis et al., 2010). These fears and attitudes as well as a lack of knowledge about treatments such as stimulants may lead to decreased acceptability ratings of medication for ADHD (Partridge et al., 2012, 2014; Sciutto, 2015). Additionally, 
perception of childhood symptoms (e.g., externalizing vs. internalizing) as well as their own selfperceived parenting effectiveness affects what types of treatment parents prefer (Bennet et al., 1996). Finally, previous patient-doctor relationships also affect treatment decision-making (Coletti et al., 2012; Ha \& Longnecker, 2010; Kraetschmer et al., 2004; Vermeire et al., 2001). Much of the previous research reviewed above has used case vignettes and hypothetical children in the research design. As suggested by Jiang and colleagues (2014), however, there may be a difference between parental attitudes towards treatment for a hypothetical child compared to views for their own children. Thus, research that focuses only on hypothetical scenarios may be limited in revealing what barriers are actually most significant to treatmentseeking. In addition to increased ecological validity, there is reason to investigate parental attitudes about treatment in reference to their own children without an ADHD diagnosis (i.e., non-treatment-seeking). The goal of this line of research is to determine how parents' views of treatment may vary for their own children compared to their views for someone else's child in the context of their child's own symptoms (or lack of symptoms).

The current study will focus on non-treatment-seeking parents. Treatment decision making studies have historically focused on attitudes towards case vignettes and hypothetical children or parents whose children are being assessed for, or already have, a diagnosis of ADHD (i.e., parents that have already made the decision to seek professional help). Mental health treatments only work for those who access them. To the extent that research on treatmentseeking attitudes is limited to these currently examined samples, the reasons that parents who might need, but do not seek, treatment for their own child with ADHD remain unexamined. Parents who have made treatment contact for their child have overcome barriers to treatment and may differ from those who do not make treatment contact for their child. 
Given the high delay from symptom onset to treatment that exists ADHD (Dakwar et al., 2014), this is a significant issue to further study. Understanding the trajectory of treatmentseeking attitudes and behaviors in a sample who has not yet sought treatment can help to further extend our understanding of treatment decision-making. Although the existing research base has provided significant and important information for beginning to understand why parents delay treatment for their children's ADHD, the crucial next step is to understand what separates those who have overcome barriers to seek treatment and those who have not yet pursued treatment. The current study aims to investigate what barriers are most salient in this understudied sample in their relation to treatment-related attitudes.

Furthermore, the majority of studies have asked participants to rate the acceptability and effectiveness of interventions, which although certainly related, may over estimate actual treatment-seeking behaviors. For example, although psychological models of behavior often cite attitudes as the best predictor of someone's behavior, intentions and attitudes only account for approximately $28 \%$ of the variance in predicting behavior (Sheeran, 2002). This is a significant portion, and thus attitudes and intentions should be valued when attempting to investigate treatment-seeking behaviors. However, attitudes and intentions alone are limited in their ability to completely predict behavior, and it may be insufficient to examine attitudes and intentions in isolation, especially in a non-treatment-seeking sample that has not initiated any treatment behavior.

There are several ways that this problem may be addressed. Future research could distinguish treatment-seeking intent (e.g., "I would ask my doctor for medication.”) versus treatment-seeking behavior (e.g., "Medication is safe for use."). However, since intentions and attitudes are, in isolation, limited in predicting behavior (Sheeran, 2002), behavioral measures of 
actual treatment-seeking (e.g., seeking out more information, making an appointment for their child) may provide different and potentially more informative data about treatment decision making. To the extent that parents serve as gatekeepers to treatment for their children, their attitudes, opinions, and actual behaviors are each important towards informing intervention developments aimed at increasing treatment access for children with ADHD. By increasing treatment access, the ultimate goal of reducing the long-term negative outcomes associated with ADHD may be realized.

The current study aims to investigate previously identified factors in parents of children with ADHD and how these factors relates to not only treatment attitudes but also informationseeking behaviors in a sample of parents whose children have not been diagnosed with ADHD. A majority of parents of a child with ADHD use the Internet to find information about ADHD and its treatments (Sage et al., 2017). However, little has been done to examine the factors associated with this information-seeking behavior. Parents' ability to recognize ADHD symptoms as characteristic of the disorder, parenting-self-efficacy, parent ratings of satisfactions with past providers for themselves and their children, beliefs about the causal attributions of ADHD, knowledge about ADHD and ADHD treatments, and stigma towards ADHD will be examined as predictors towards parents' treatment attitudes and information-seeking behavior.

To our knowledge, this is the first study that will examine these factors together as well as their relation to a measure of information-seeking behavior, rather than attitudes alone. Understanding what factors influence behaviors, not only attitudes, is important because someone may not hold strong negative attitudes towards treatment, but, for a variety of reasons, not actually seek treatment. Further, efforts to decrease barriers to mental health treatments have historically included information campaigns (Perry et al., 2014; Pinfold et al., 2003; Schachter et 
al., 2008; Spence et al., 2005; Watson et al., 2004; Wyn, Cahill, Holdsworth, Rowling, \& Carson, 2000). To the extent that we do not understand factors that affect information-seeking and-acceptance in those that have not yet considered treatment (but may in the future), the utility of these programs is unclear. Moreover, without the understanding of the factors that affect behaviors, efforts to increase treatment-seeking are limited. If we wish to affect behavior, we must study behavior.

\section{Hypotheses}

Based upon the research cited above in the literature on general attitudes (e.g., case vignettes, not about their own child) and treatment-seeking parents of children with ADHD, the following hypotheses will be tested in a non-treatment-seeking sample (See Figure 1).

Hypothesis 1a: Perceptions of ADHD symptoms as externally controlled, high parenting self-efficacy, high stigma about ADHD, and high misconceptions about ADHD will be significantly associated with more negative attitudes about ADHD medication (Bennet et al., 1996; Jiang et al., 2014; Johnston et al., 2008).

Hypothesis 1b: Personal experiences and success with ADHD medication increases positive ratings of future medication treatment (Liu et al., 1991). Parents prefer collaborative relationships with treatment providers (Coletti et al., 2012; Ha \& Longnecker, 2010; Kraetschmer et al., 2004; Vermeire et al., 2001). Based upon both, it is hypothesized that greater parent satisfaction with treatment providers for themselves or their children will be significantly associated with positive ADHD treatment attitudes.

Hypothesis 1c: Ability to recognize symptoms of ADHD correctly and knowledge about ADHD will be significantly associated with positive attitudes toward ADHD treatments, consistent with previous research (Bennet et al., 1996; Sciutto, 2015). 
Hypothesis 2a: There is currently no research that has examined information-seeking behavior. Thus, these hypotheses are necessarily exploratory. However, we hypothesize that, consistent with Hypothesis 1a, high misconceptions about ADHD treatments and high stigma will be negatively associated with information-seeking behavior. Given that parenting selfefficacy and perceptions of ADHD of externally controlled and impairing are positively associations with behavioral treatments (Jiang et al., 2014; Johnston et al., 2008), we hypothesize that these variables will be positively associated with ADHD information-seeking behavior.

Hypothesis 2b: Consistent with Hypothesis 1b, greater satisfaction with treatment providers for themselves or their children will be significantly and positively associated with ADHD information-seeking behavior.

Hypothesis 2c: Consistent with Hypothesis 1c, ability to recognize symptoms of ADHD and knowledge about ADHD and evidence-based treatment will be significantly and positively associated with ADHD information-seeking behavior.

Hypothesis 3: Finally, since attitudes and intentions are significant predictors of behavior (Sheeran, 2002), treatment attitudes are hypothesized to be significantly and positively associated with the behavioral measure of treatment/information-seeking. However, this association will likely be moderate in strength as non-treatment-seeking parents may report positive attitudes, but do not actually intend on seeking more information about treatment.

\section{Methods}

\section{Participants}

Participants were recruited from two sites: (a) a traditional, inclusive summer camp of approximately 1000 campers in the Northeastern United States and (b) Amazon's Mechanical Turk (mTurk). The purpose of using two ascertainment sites was to increase the diversity and 
representativeness of the sample. The final sample included in analyses was 169 parents $(n=36$ from the summer camp; $n=133$ from mTurk).

Parents recruited from the summer camp (1) were English speaking and (2) had a child enrolled in the summer camp. All parents of campers from the summer camp were invited to participate. Of the 51 participants who initially consented to the study, $43(84.3 \%)$ completed at least half of the survey. Of these 43 participants, 7 had children with ADHD (16.3\% of camp sample) and thus were excluded from the sample (final sample $n=36$ ). The camp sample was $2.8 \%$ men and $100 \%$ White. The mean age of the parents was 42.44 years $(S D=6.93)$, and $92.2 \%$ had completed some college or more. These demographic data are consistent with those reported in previous studies conducted at the same summer camp (Kingery, Peneston, Rice, \& Wormuth, 2012).

Amazon's mTurk is an online platform in which potential research participants can access a variety of research studies referred to as "Human Intelligence Tasks" (HITs). Participants select HITs of interest and are paid for their time (Behrend, Sharek, Meade, \& Wiebe, 2011). Participant data derived from mTurk data demonstrates equivalent or higher psychometric quality as data from published research using both traditional and other web-based samples, including representing more diverse populations than typical internet-based and college samples (Behrend et al., 2011; Buhrmester, Kwang, \& Gosling, 2011; Shapiro, Chandler, \& Mueller, 2013). In mTurk, researchers either approve or disapprove of a worker's HIT once it has been completed. This increases participant motivation to complete HITs. Workers are also prevented from changing reported demographic characteristics to complete studies with demographic requirements. 
To be eligible to participate, mTurk participants had to: (1) reside in the U.S. and (2) have completed at least $95 \%$ of their previous HITs successfully. A third inclusion criteria (3) be a parent, was added for this study. All 152 mTurk participants completed the entire survey.

Nineteen participants identified that they had a child with ADHD (12.5\% of mTurk sample) and were thus dropped from the analyses (final mTurk sample $n=133$ ). The sample was $33.1 \%$ men and $91 \%$ White. The mean age was 39.41 years $(S D=9.62)$, and $82.7 \%$ had completed some college or more. These demographic characteristics are comparable to those reported in previous mTurk samples (Behrend et al., 2011).

As the current study aimed to examine non-treatment-seeking individuals, participants whose child had ADHD were excluded from analyses $(n=26$; final sample $n=169)$. Chi square analyses indicated no significant site differences on percentage of children with ADHD $\left(X^{2}(1)=\right.$ $0.55 ; p=.46)$.

After the two sites were combined, the omnibus sample $(n=169)$ was $26.6 \%$ men and 92.9\% White. The mean age was 40.00 years $(S D=9.22)$, and $85.8 \%$ had completed some college or more. Participants who were missing more than half of their data points $(n=8$; all from the camp site) were excluded from analyses. On remaining data, mean series multiple imputations were conducted to replace missing values for data that was non-demographic and scalar in accordance with recommendations for handling missing data (Raaijmakers, 1999).

ADHD symptoms and impairment ratings. Despite being non-treatment-seeking, child ADHD symptoms (See Table 1) indicated that parents reported elevated total ADHD, hyperactivity-impulsivity, and inattention symptoms in their children based on gender- and agenormed scores $\left(70.76^{\text {th }}, 72.83^{\text {rd }}, 68.26^{\text {th }}\right.$ percentiles, respectively) (DuPaul, Power, Anastopoulos, \& Reid, 2016). Additionally 69 parents (40.8\%) reported that their children's global impairment 
rating was in the clinically significant impairment range (Fabiano et al., 2006). Time spent on ADHD information page was not associated with parents' rating of child impairment $(r=.10, p$ $=.20)$, however, it was marginally related to ADHD-RS-5 total symptoms $(r=.15, p=.05)$. No significant differences in child symptoms emerged between those who sought additional more information about ADHD resources and those who did not $\left(F(1,157)=1.11, p=.29 ; \eta^{2}=.01\right.$. However, parent rated child functional impairment was higher for those who sought additional information about $\mathrm{ADHD}$ resources $\left(F(1,157)=12.56, p=.001 ; \eta^{2}=.07\right.$; sought more information $M=2.92 ; S D=1.97$; did not seek more information $M=1.48 ; S D=1.61$ ).

\section{Procedure}

All campers were given a letter for their parents explaining the study and inviting the parents to go to a Qualtrics link if interested. The study was also advertised on parents' electronic camp registration account. Parent participants from the summer camp were compensated by entrance into a weekly raffle for a $\$ 100$ gift card. Chances of selection were approximately 1 in 7 . Parents from the summer camp received a link to be entered into the raffle at the end of the Qualtrics survey. The study was also advertised on mTurk's HIT homepage. All mTurk parent participants were compensated with a $\$ 1$ credit to their mTurk account, which is in compliance with mTurk standards (Buhrmester et al., 2011).

Informed consent was presented at the beginning of the survey where participating parents either accepted or declined to participate (97.1\% accepted). Parents completed all measures on Qualtrics. The duration of the study protocol was approximately 25 minutes (range: $11-60$ minutes). Two validity checks (e.g., "The answer to the following question is blue") were embedded in the survey to assess for attentiveness. All 169 participants correctly answered both validity checks. 


\section{Measures}

Demographic / Parent self-report of symptoms. Demographic data was collected on parent race, gender, ethnicity, education level, age, past and current mental health diagnoses, past and current medication use, ratings of satisfaction with past treatment providers, marital status, and number of children. Parents were asked to provide demographic data for their child with the "most challenging behavior" and use this target child when completing study measures (e.g., ADHD symptom ratings, etc.). Information was collected on that child's gender, age, grade level, past and current mental illness diagnoses, ADHD symptoms and functional impairment ratings, past and current medication use and parent ratings of satisfaction with past child treatment providers. Ratings of satisfaction with past treatment providers, for both self and child, were assessed with the questions, "What has been your experience with your [child's] treatment providers?" rated on a 5-point Likert scale from "extremely dissatisfied" to "extremely satisfied."

Patient Health Questionnaire (PHQ-4). The PHQ-4 is a 4-item brief screening tool that measures symptoms of anxiety and depression (Kroenke, Spitzer, Williams, \& Löwe, 2009). High scores on the PHQ-4 are associated with higher levels of internalizing symptoms. The PHQ-4 has good construct validity and internal consistency $(\alpha>$.80) (Kroenke et al., 2009). In the current sample the PHQ-4 demonstrated good internal consistency $(\alpha=.87)$. Parents completed the PHQ-4 about themselves.

Adult ADHD Self-Report Scale (ASRS) Screener. The ASRS screener is a six-item measure generated from symptoms of ADHD in adults (Kessler et al., 2005a). The items represent DSM-IV criteria and can be divided into 4 inattentive symptoms and 2 hyperactiveimpulsive symptoms. Scores range from 0 to 24 where higher scores indicate higher levels of 
symptoms of ADHD. The screener demonstrates high sensitivity (68.7\% accurate), specificity (99.5\% accurate), and total classification accuracy $(97.9 \%)$ in examining adults with and without ADHD. In the current sample internal consistency was good $(\alpha=.84)$. Parents completed the ASRS about themselves.

\section{Symptom recognition.}

Clinical Vignettes. Vignettes with a precedence in the child stigma literature (Jorm, Wright, \& Morgan, 2007; O’Driscoll, Heary, Hennessy, \& McKeague, 2012) were adapted to depict a child with ADHD, social anxiety disorder, and "daily troubles." An additional control vignette characterizing asthma was added (Burns, 2013). Social anxiety disorder was selected as a comparison vignette as previous research suggests that symptom recognition is low for this condition (Coles et al., 2016). Diagnostic labels were not used within the vignettes.

Two questions followed each clinical vignette to assess perceptions of whether the case vignette symptoms warranted professional treatment. First, participants responded to the prompt "[NAME] has a problem that needs professional help" using a 1-9 Likert scale where 1 is "strongly disagree" and 9 is "strongly agree." Next, the open-ended question "What do you think is going on with [NAME]?" assessed participants' ability to accurately label symptoms of the 4 conditions (ADHD, social anxiety, asthma, "daily troubles"). Codes were replicated from a previous study that used this methodology (i.e., $0=$ no mental illness label, $1=$ vague mental illness label, 2 = correct mental illness label; see Taylor, Ponzini, \& Schofield, unpublished manuscript for more information). All responses were coded by two independent raters blinded to the hypotheses of the study (IRR $\geq 84.04 \%$ ). All discrepant codes were discussed among independent raters and the first author until consensus was reached.

\section{Mental Health Stigma.}


Attention Deficit Hyperactivity Disorder (ADHD) Stigma Questionnaire (ASQ). The ASQ is a 26-item questionnaire used to assess public stigma towards ADHD (Kellison, Bussing, Bell, \& Garvan, 2010). There are three distinct subscales: Disclosure Concerns (e. g., "People with ADHD work hard to keep it a secret"), Negative Self-Image (e. g., "People with ADHD feel ashamed of having ADHD") and Concerns with Public Attitudes (e.g., "People with ADHD are treated like outcasts"). The current measure was adapted slightly from the original ASQ to address parents' beliefs about their children (e.g., "If my child had ADHD, we would work hard to keep it a secret"). The ASQ is measured on a 4-point Likert scale (1 is strongly disagree and 4 strongly agree) with higher scores indicating higher public stigma. The original ASQ has good internal consistency $(\alpha=0.93)$, test-retest reliability $(\mathrm{ICC}=.71)$, and convergent/divergent validity (Kellison et al., 2010). The adapted ASQ demonstrated good internal consistency in this sample $(\alpha=.97)$, at levels consistent with previous research (Kellison et al., 2010). A Pearson correlation between the attribution questionnaire (Corrigan, 2008) stigma score for ADHD and the ASQ was computed to determine convergent validity. There was a significant correlation between the ASQ and the AQ-9 $(r=.40, p<.001)$. Thus, the adapted ASQ demonstrates solid psychometric properties.

Attribution Questionnaire (AQ-9). General stigma was measured with an adapted version of the 9-item AQ-9 (Corrigan, 2008). The AQ-9 measures self-reported levels of stigma towards someone who has a mental illness. Each item is rated on a $1-9$ Likert scale. Participants read the 4 clinical vignettes (Jorm et al., 2007; O’Driscoll et al., 2012) described above. Following each vignette, AQ-9 questions were rephrased to address the subject of the vignette and assess stigma (e.g., anger toward the individual, perceived dangerousness). An average stigma attitude score was calculated across the AQ-9 questions for each of the 4 
vignettes to create an overall assessment of stigma attitudes towards a particular disorder, a strategy that has precedence in the literature (Pinto, Hickman, Logsdon, \& Burant, 2012). In the current sample internal consistency was poor for social anxiety disorder $(\alpha=.56)$, $\operatorname{ADHD}(\alpha=$ $.58)$, and asthma $(\alpha=.59)$, and acceptable for daily troubles $(\alpha=.70)$. This measure was used solely to validate the ASQ.

Causal Attributions Scale. Causal beliefs about the 4 vignette characters (ADHD, asthma, social anxiety disorder, and daily troubles) were measured with the Causal Attribution Scale (Martin, Pescosolido, \& Tuch, 2000). The Causal Attribution Scale is a six-item questionnaire that assesses whether participants believe the cause of a problem is medical/genetic (e.g., vignette characters' "parent or other members of family have the same condition"), social (e.g., vignette characters' "parents did not raise him/her right"), or moral/individual (e.g., Vignette character "is not trying hard enough to get better"). Participants were asked "If any of these things could be a part of the vignette characters' condition?" using a 7-point Likert scale whereas 1 represents "not at all true" and 7 represents "very true." In the current sample internal consistency was poor for social anxiety disorder $(\alpha=.58)$ and $\operatorname{ADHD}(\alpha=.51)$, questionable for asthma $(\alpha=.65)$, and good for daily troubles $(\alpha=.84)$.

Three items ("[his] parents did not raise him right" indicating upbringing, "[he] is not trying hard enough to get better" indicating effort, and "[he] has experienced more stressful events in his life than most people do" indicating environmental stress) were significantly correlated (all $r \mathrm{~s}>.37$, all $p s<.001$ ) and thus were combined to create a scale of external / nonbiological causal attributions in an effort to reduce Type I errors. In the current sample internal consistency was questionable $(\alpha=.63)$. Endorsement of external / non-biological causes of ADHD are important to understand to the extent that they represent a common parental 
misunderstanding of ADHD diagnosis and treatment (Bussing et al., 2012; Pescosolido et al., 2007; Pescosolido et al., 2008).

\section{Knowledge and Misconceptions.}

Strength of Belief in ADHD Knowledge Scale (SBAKS). The SBAKS is a 26-item true/false scale that measures participants' knowledge and misconceptions of ADHD treatments (Sciutto, 2015). This measure assesses both participants' knowledge and misconceptions about ADHD treatments and confidence in their answers. Confidence is rated on a 4-point Likert scale from 0 (i.e., just a guess) to 3 (e.g., I am certain). Internal consistency in ADHD knowledge and confidence was questionable to excellent (all $\alpha$ s $>0.60$ ) in the current sample. A Pearson correlation between another test of mental health knowledge, the Knowledge of Mental Health Test (KHMT) (see below) (Taylor, Ponzini, \& Schofield, Unpublished Manuscript) and the knowledge aspect of the SBAKS supported convergent validity $(r=.35, p<.001)$.

The Knowledge of Mental Health Test (KHMT). The KMHT is an achievement test that includes 17 questions; 8 multiple choice and 9 true/false. As expected based on guessing that occurs during an achievement test when participants have less information about a topic, overall internal consistency is poor $(\alpha=.51)$ yet acceptable in more knowledgeable participants $(\alpha=.74)$ (Taylor et al., Unpublished Manuscript). KMHT test-retest reliability is strong $(r=.86, p<.001)$. The KMHT was used solely to demonstrate convergent validity with the SBAKS. Internal consistency in the current sample was consistent with previous research $(\alpha=.56)$.

\section{Parenting Self-Efficacy.}

Parenting Self-Efficacy Scale. The Parenting Self-Efficacy Scale is a 25-item Likert scale $(1=$ not at all confident to $6=$ very confident $)$ that addresses parents' confidence in their own parenting abilities (i.e., supporting child's development and teaching their child age- 
appropriate tasks) (Suzuki, Holloway, Yamamoto, \& Mindnich, 2009). Reported internal consistency was excellent $(\alpha=.92)$. Internal consistency in the current sample was similar $(\alpha=$ .94). The measure was derived using panels of developmental experts (e.g., developmental researchers, teachers, parent education specialists) and all items were rated as important to parenting by a sample of parents across multicultural contexts (Suzuki et al., 2009). One item (i.e., teach your child to learn the alphabet) was changed to (i.e., teach your child information needed for school) to be more appropriate for a variety of ages.

\section{Child ADHD Symptoms and Impairment.}

ADHD Rating Scale - $\mathbf{5}^{\text {th }}$ Edition (ADHD-RS-5). The ADHD-RS-5 is an 18-item rating scale based on DSM-5 criteria for ADHD, consisting of inattention and hyperactivity-impulsivity subscales (DuPaul et al., 2016). Internal consistency ( $\alpha=.89$ to .96) and test-retest reliability are $\operatorname{good}(r \mathrm{~s}=.80$ to .87$)$. Factor analyses support the two-domain structure. The scale also demonstrates strong concurrent validity with other measures of ADHD and good predictive validity (DuPaul et al., 2016). Internal consistency in the current sample was consistent with previous research $(\alpha=.95)$.

Impairment Rating Scale (IRS). The IRS was developed for parents and teachers as a rating scale for severity of ADHD associated functional impairments (Fabiano et al., 2006). The IRS measures child impairment in the 8 areas of: peer, sibling, parent, and teacher relationships, academic, self-esteem, classroom/family, and global functioning. The IRS is stable over one year ( $r>.54$ for parents) and reliable across informants $(r=.78)$. It also demonstrates good concurrent, convergent, and discriminant validity. The IRS is effective in discriminating between children with and without ADHD (i.e., sensitivity above .65) (Fabiano et al., 2006). Given that the aims 
of the current study did not focus on specific domains of child impairment, only the global impairment scale was examined.

\section{Treatment Attitudes.}

Questionnaire on Attitudes towards Treatment of ADHD (QATT). Attitudes towards common ADHD treatments were assessed using the parent report version of the QATT (Ferrin et al., 2012). The QATT is measured on a 5-point Likert scale, with 0 as "always false" and 4 "always true." The QATT measures three distinct categories of treatment attitudes: worries regarding treatment (5 questions), insight into illness and the need for medical treatment (5 questions), and self-perception and patient-doctor relationship (3 questions). Worries regarding treatment are characterized by general worries, worries about the possible side effects of medication, beliefs that doctors over-prescribe, and belief that medication should only be used in extreme circumstances; higher scores indicate more worries about treatment. Insight is characterized by understanding the need for medical treatment, the importance of adhering to treatment as prescribed, and motivation to follow treatment plans; higher scores indicate more insight about treatment. Self-perception and the patient-doctor relationship is associated with contentedness with self and relationship with one's doctor, higher scores indicate better selfperception and patient-doctor relationship. The internal consistency is adequate $(\alpha>.66)$ for the first two subscales, but weaker $(\alpha=.58)$ for the self-perception and patient-doctor relationship factor. Internal consistency in the current sample was comparable $(\alpha=.65 ; .76 ; .55$, respectively). Convergent validity with measures of treatment adherence is high (Ferrin et al., 2012).

Treatment-Seeking Behavior.

Information-Seeking Measure. At the end of the survey, participants were presented 
with a mock webpage containing accurate information about ADHD and ADHD treatments. Time spent on this page was recorded via Qualtrics. Participants were then provided with the option to seek additional information about local community resources for ADHD assessment and treatment by clicking "yes I would like more information." Decisions were recorded and dichotomized into sought additional information / did not seek additional information.

\section{Preliminary Analyses}

Analyses were conducted in SPSS-24. Power analyses were conducted in G*Power. Power analyses. A priori power estimates using effect sizes from previous research examining predictive factors (e.g., knowledge and perceptions of symptoms) of treatmentseeking (Bennet et al., 1996; Sciutto, 2015) were calculated using G*Power. Assuming 80\% power to detect significant associations, an alpha level of .05 , a moderate effect size $\left(f^{2}=.10\right)$, and two predictors, a sample size of 100 participants was needed to attain adequate statistical power. Using the same parameters, except with four predictors (consistent with Hypothesis 3), a sample size of 125 was needed to attain adequate statistical power. Thus, our study was adequately powered.

Data inspection. Before conducting analyses, as suggested by Tabachnick and Fidell (2007), outlier data points were truncated to 3 SDs above/below the group mean of each measure. This practice helps to remove measurement error (Costa, 2014), allowing for variables to be changed to less extreme, but still high values. This truncation reduced the ability of an outlier to unduly influence statistical significance through Type I or Type II errors. A total of eight data points were truncated to 3SDs within the group mean. Notably, analyses including and excluding outliers were comparable. In this way, the analyses were not influenced by any influential cases. 
Multicollinearity and normality assessment. Multicollinearity may increase the variance of the regression coefficients and result in a lack of statistical significance when the individual predictor is, in fact, significant (Type II Error), thus leading to inaccurate conclusions. Before testing hypotheses, multicollinearity was assessed through examination of the correlation matrix between variables within each hypothesis (see Table 2). A correlation coefficient of .80 was used as a cutoff, as a strong correlation suggests that the variables are measuring the same/very similar constructs (Tabachnick \& Fidell, 2007). In addition, during hypothesis testing, multicollinearity diagnostics were also conducted for each regression analysis using variance inflation factor (VIF). The VIF is an index of how much variance of a regression coefficient is increased due to multicollinearity and is a widely used method of detecting multicollinearity (Montgomery, Peck, \& Vining, 2001). As suggested by previous research (Montgomery et al., 2001), independent variables that have a VIF greater than 5 should be further investigated. Based on the correlation matrix (see Table 2) and VIF (reported in Tables 4 and 5), none of our models indicated need for concern about the effects of multicollinearity on results.

In addition, the skewness and kurtosis of dependent and independent variables were calculated. As indicated by the parameter (e.g., +/-2) proposed by West, Finch, and Curran (1995), Time Spent on ADHD Information Page (skewness $=1.96, S E=.19 ;$ kurtosis $=3.84 S E$ $=.38$ ) and endorsements of $\mathrm{ADHD}$ as externally caused (skewness $=1.83, S E=.18$; kurtosis $=$ $3.43, S E=.35)$ both violated the assumption of normal distribution. Therefore, these two variables were transformed using a logarithmic transformation so that each demonstrated a normal distribution (Osborne, 2005).

Preliminary analysis of data collection sites. Chi square analyses and ANOVAs using weighted means to correct for unequal sample sizes were conducted to assess for ascertainment 
site differences. Results indicated significant differences between recruitment site on several variables (See Table 1). Significant differences were detected in parent gender $\left(X^{2}(1)=13.32 ; p\right.$ $<.001)$, parent education level $\left(X^{2}(1)=5.03 ; p<.01\right.$, parent symptoms of depression $(F(1,282)$ $=3.89, p=.05 ; \eta^{2}=.01$ ), parent ratings of satisfaction with previous treatment providers $\left(F(1,291)=8.55, p=.004 ; \eta^{2}=.03\right)$, and ratings of satisfaction with child's previous treatment providers $\left(F(1,291)=6.95, p=.01 ; \eta^{2}=.02\right)$. The mTurk sample demonstrated slightly higher mean levels of depression, completed fewer years of formal education, included more males, and were less satisfied with both parent and child treatment providers than the camp sample. No significant effects of site emerged on other demographic or independent variables or any study dependent variables (all $p \mathrm{~s}>.08$ ). Further, inspection of the interaction terms indicated no moderation effects of site (all $p \mathrm{~s}>.06$ ), except for the interaction between Susceptibility to ADHD Stigma and site for insight into the need for treatment $\left(r^{2}=.06, F(2,166)=4.92, p=.01\right)$. However, Susceptibility to ADHD Stigma was not significantly associated with insight into need for treatment $\left(r^{2}=.02, F(1,167)=3.06, p=.08\right)$. Thus although site may have been a possible moderator, this non-significant relation was not explored in hypothesis testing.

Nonetheless, given the site differences on an independent variable (provider satisfaction) and the significant interaction (Susceptibility to ADHD Stigma), site was added as the first step in the regression in analyses for all hypotheses. However, adding site into the model did not change the direction or significance of relations. As site was not associated with any dependent variables and adding site into the model did not change the direction or significance of relations, results are presented without site controlled to enhance power to detect significant associations. Given non-significant results for effects of site for other analyses, site was not controlled for in any of our other analyses. See Table 1 for all demographic data organized by site. 
Preliminary analysis of demographic comparisons. ANOVAs and chi square analyses for parent gender using weighted means to correct for unequal sample sizes were also conducted on all dependent variables to assess for potential significant differences. Women spent more time on the ADHD information page $\left(F(1,291)=11.67, p=.001 ; \eta^{2}=.04\right)$ and held more positive total treatment attitudes $\left(F(1,291)=7.52 p=.01 ; \eta^{2}=.03\right)$. Thus, gender was included as a step in hypothesis testing models. Notably, similar to adding site to models, adding gender in the regressions did not change the direction or significance of relations, so results are presented without gender as a step to retain power to detect significant associations. No other significant gender differences were found for any dependent variables (all $p \mathrm{~s}>.10)$.

Between subjects ANOVAs and chi square analyses were conducted between child gender and all dependent variables to assess for significant differences. No significant gender differences were found on any dependent variable (all $p \mathrm{~s}>.07$ ). Therefore, child gender was not included in any further analyses.

Pearson's bivariate correlations examined associations between child age and ratings of child medical provider satisfaction or ratings of parent medical provider satisfaction, given that older children may have had more interaction with treatment providers, solely due to age. There were no significant relations for either $(r=.02, p=.80 ; r=.09, p=.23$, respectively). Therefore, child age was not included in any further analyses.

\section{Planned Analyses}

Variable reduction. A principal components analysis (PCA) with an orthogonal rotation was used to determine if there were latent components that emerged from the independent variables (perceptions of ADHD symptoms as externally controlled, parenting self-efficacy, stigma about ADHD, and misconceptions about ADHD). A Varimax rotation with Kaiser 
normalization was conducted and the rotated component matrix was examined. Components with an eigenvalue $>1$ were included as independent variables in hypothesis testing models. Index variables, called components, are created from a larger set of measured variables by using weighted averages of a set of variables.

Correcting for inflation of family-wise error rates. To adjust for increased risk of Type I error when conducting multiple tests, the Bonferroni correction for family-wise error rates was used. Alpha (set at .05) was divided by the number of tests conducted (i.e., $n=4)$ ). Significance level was set at $p<.0125$.

Hypothesis 1a: A linear regression will be conducted to determine if the latent components that emerged from the component analysis (i.e., Misunderstanding of ADHD and Susceptibility to ADHD Stigma) are associated with more negative attitudes about ADHD medication (as measured by the QATT). Components will be entered simultaneously.

Hypothesis 1b: A linear regression will be conducted to determine if positive parental ratings of satisfaction with their own and their child's past treatment providers is associated with more positive ADHD medication attitudes. Satisfaction variables will be entered simultaneously.

Hypothesis 1c: Using the SBAKS knowledge score to assess knowledge and responses to clinical vignettes to assess symptom recognition, a linear regression will be conducted to examine these factors' association with attitudes towards ADHD medication. Both independent variables will be entered simultaneously.

Hypothesis 2a: In the same process as in Hypothesis 1a, a linear regression will be conducted to examine if the latent components that emerged from the component analysis are associated with time spent on the ADHD information page. A logistic regression will be 
conducted to determine if these components are associated with seeking additional information about ADHD resources.

Hypothesis 2b: Consistent with Hypothesis 1b, a linear regression will be conducted to examine the relation between parents' satisfaction with their own or their child's health providers and time spent on the ADHD information page. A logistic regression will be conducted to determine if previous satisfaction with providers is associated with seeking additional information about ADHD resources.

Hypothesis 2c: Consistent with Hypothesis 1c, a linear regression will be conducted to examine if ADHD knowledge and symptom recognition are significantly associated with time spent on the information page. A logistic regression will be performed to determine if these factors are associated with seeking additional information about ADHD resources.

Hypothesis 3: Finally, a linear regression will be used to examine if treatment-seeking attitudes about ADHD medication are associated with time spent on the ADHD information page. A logistic regression will be used to determine if treatment-seeking attitudes about ADHD medication are associated with seeking additional information about ADHD resources. Variables will be entered simultaneously.

\section{Results}

See table 3 for results of factor analysis. See Tables 4 and 5 for complete hypothesis testing results.

\section{Variable reduction}

Two distinct latent components emerged from the principal components analysis (see Table 3 ). Component 1 explained $36.87 \%$ of the variance (Eigen value $=1.48$ ) and component 2 explained an additional $28.22 \%$ of the variance (Eigen value $=1.13$ ). Perceptions of ADHD as externally 
controlled and high misconceptions loaded on Component 1 (labeled, Misunderstanding of $A D H D$ ) and low parenting self-efficacy and high ADHD stigma loaded on Component 2 (relabeled, Susceptibility to ADHD Stigma). Given the significant negative relation between parenting self-efficacy and ADHD stigma $(r=-.30, p<.001)$, Susceptibility to ADHD Stigma was chosen to label this component. Individuals who have greater beliefs in their own abilities as parents may have less worries and fears about how others would view themselves or their child if their child had ADHD.

\section{Hypothesis 1a}

Misunderstanding of ADHD and susceptibility to ADHD stigma were not significantly associated with the total score on the QATT $\left(r^{2}=.03, F(2,166)=2.25, p=.11\right)$. Overall models for worries about treatment $\left(r^{2}=.07, F(2,166)=6.06, p=.003\right)$, insight into need for treatment $\left(r^{2}=.08, F(2,166)=7.38, p<.001\right)$, and self-perception/patient-doctor relation were significant $\left(r^{2}=.15, F(2,166)=14.23, p<.001\right)$.

Regression analyses indicated that misunderstanding of ADHD was the component driving significance for worries about treatment $(t=3.30, \beta=.25, p<.001)$ and insight about treatment $(t=-3.39, \beta=-.25, p<.001)$. Greater misunderstanding about ADHD was positively associated with worries about treatment and negatively associated with insight about treatment. For self-perception and patient-doctor relationship, results suggest that susceptibility to ADHD stigma drove the association $(t=-5.35, \beta=-.38, p<.001)$. Less susceptibility to ADHD stigma was associated with greater self-perception and patient-doctor relationships in this nontreatment-seeking sample of parents.

\section{Hypothesis 1b}


Regression analyses suggested that one's own or child's medical provider was not associated with QATT total treatment attitudes $\left(r^{2}=.01, F(2,166)=.53, p=.69\right)$ or selfperception and patient-doctor relationships $\left(r^{2}=.02, F(2,166)=2.43, p=.09\right)$. The overall models for worries about treatment $\left(r^{2}=.16, F(2,166)=15.23, p<.001\right)$ and insight about need for treatment $\left(r^{2}=.07, F(2,166)=6.17, p=.003\right)$ were significant.

Results indicated that more positive experiences with a child's providers was associated with lower worries about treatment $(t=-3.02, \beta=-.27, p=.003)$. More satisfaction one's own provider was associated with increased insight about treatment $(t=2.50, \beta=.24, p=.01)$ in this non-treatment-seeking sample of parents.

To better understand the unexpected finding that satisfaction with treatment providers was not associated with the QATT self-perception and patient-doctor relationships scale, a bivariate correlation was conducted to determine if, for this association, the two domains (i.e., self-perception, two questions vs. patient-doctor relationship, one question) in the QATT factor demonstrated differential relationships with previous provider experiences. A significant correlation between both satisfaction with one's own provider $(r=.36, p<.001)$ and child's provider $(r=.28, p<.001)$ was observed with endorsements of positive relationship with treatment providers. No significant correlations were observed between either satisfaction with own or child treatment providers and either of the two self-perception items of the factor (all $p \mathrm{~s}$ $>$.17).

\section{Hypothesis 1c}

ADHD knowledge and symptom recognition were not significantly associated with QATT total treatment attitudes $\left(r^{2}=.004, F(2,166)=.30, p=.74\right)$ or self-perception and patientdoctor relationship $\left(r^{2}=.001, F(2,166)=.10, p=.90\right)$. Knowledge and symptom recognition 
trended towards significance with worries about treatment attitudes yet did not survive Bonferroni correction $\left(r^{2}=.05, F(2,166)=3.98, p=.02\right)$. ADHD knowledge and symptom recognition were significantly associated with insight about need for treatment $\left(r^{2}=.12\right.$, $F(2,166)=11.40, p<.001)$.

Knowledge about ADHD drove the significant association in the model $(t=4.49, \beta=.36$, $p<.001)$; greater ADHD knowledge was associated with significantly more treatment insight in this non-treatment-seeking sample of parents. The trending significant relation in the worries about medication model was also driven by knowledge $(t=-2.63, \beta=-.22, p=.01)$; lower ADHD knowledge was associated with more worries about treatment.

\section{Hypothesis 2a}

The linear and logistic regressions indicated that misunderstanding of ADHD and susceptibility to ADHD stigma were not significantly associated with time spent on the ADHD information page $\left(r^{2}=.002, F(2,166)=.19, p=.83\right)$ or seeking additional information about ADHD resources (Wald $X^{2}(2)=.37, p=.83$ ).

\section{Hypothesis 2b}

Satisfaction with one's own or child providers were not significantly associated with time spent on the ADHD information page $\left(r^{2}=.03, F(2,166)=2.26, p=.11\right)$ or seeking additional information about ADHD resources (Wald $X^{2}(2)=2.39, p=.30$ ).

\section{Hypothesis 2c}

ADHD knowledge and symptom recognition were not significantly associated with time spent on ADHD information page $\left(r^{2}=.002, F(2,166)=.19, p=.83\right)$ or seeking additional information about ADHD resources (Wald $X^{2}(2)=1.65, p=.44$ ).

\section{Hypothesis 3}


Linear regression indicated that QATT total treatment attitudes, worries about treatment, insight about need for treatment, and self-perception and patient-doctor relationship scales were not related to time spent on ADHD information page $\left(r^{2}=.04, F(4,164)=1.86, p=.12\right)$. Logistic regression indicated that QATT total treatment attitudes, worries about treatment, insight about need for treatment, and self-perception and patient-doctor relationship were not significantly associated with desire to learn more about ADHD resources (Wald $X^{2}(8)=8.84, p$ $=.36)$.

\section{Discussion}

Understanding the factors that predict ADHD treatment attitudes in a non-treatmentseeking sample of parents was the primary goal of this study. While these parents were not currently seeking treatment for their child's ADHD symptoms, at the group level, elevated levels of ADHD symptoms were reported (DuPaul et al., 2016). Likewise, a significant percentage of parents (40.8\%) indicated that their child demonstrated global functional impairment (Fabiano et al., 2006). Misconceptions about ADHD and external attributions about the cause of ADHD were associated strongly with each another. Likewise, high stigma ratings and lower parenting self-efficacy were associated strongly with one another.

Variables associated with treatment attitudes in other studies (Bennet et al., 1996;

Johnston et al., 2008; Sciutto, 2015) were also predictive in a non-treatment-seeking sample of parents. In both treatment-seeking and non-treatment-seeking parents, attitudes towards ADHD treatment were best predicted by misunderstanding of ADHD, susceptibility to ADHD stigma, and satisfaction with past providers. In particular, in the current study, susceptibility to stigma, satisfaction with children's providers, and knowledge about ADHD and ADHD treatments were significantly associated with different, yet important, aspects of treatment attitudes. 
Susceptibility to ADHD stigma was strongly related to poorer self-perceptions and patient-doctor relationships, satisfaction with a child's past treatment provider was robustly associated with worries about treatment, and ADHD knowledge was strongly related to insight into the need for treatment. Attitudes towards ADHD treatment were not, however, predictive of seeking additional information about ADHD resources. This has a variety of implications for future research and clinical application related to current initiatives to increase evidence-based diagnosis and treatment contact. Further, the strongest relations highlighted in these results indicate avenues for altering various aspects of treatment attitudes.

\section{Hypothesis 1a - Predicting Attitudes About ADHD Medication}

Misunderstanding ADHD. Misunderstanding ADHD was associated positively with parental worries about treatment and associated negatively with parental insight about treatment. These findings are consistent with previous research which reported that mothers who viewed their own child's ADHD symptoms as external / non-biological demonstrate disfavor for pharmacological treatments (Johnston et al., 2008). Likewise, others have reported that possessing misconceptions about ADHD and having low knowledge of ADHD is associated with lower acceptability ratings for ADHD medications (Bennet et al., 1996; Sciutto, 2015). Taken together, in both treatment-seeking and non-treatment-seeking samples, parents with a better understanding of ADHD and its evidence-based treatments have more positive medication treatment attitudes.

Misunderstanding of ADHD (e.g., viewing ADHD as externally / non-biologically caused due to poor parenting) is associated with greater worries about ADHD treatment. Previous research suggests that parental recognition of symptoms or behavioral problems in their children is a strong predictor of accessing all types of services, yet many parents do not choose to 
seek treatment, despite reporting elevated symptoms and impairment in their children (Sayal et al., 2006). That elevated ADHD symptoms and functional impairments were noted in this nontreatment-seeking sample supports these previous findings. Not pursuing ADHD treatment despite elevated ADHD symptoms and impairment is likely due to a variety of factors related to misunderstanding of ADHD, including (a) the general public places more blame and responsibility on parents of children with ADHD for their child's ADHD compared to parents of children with depression and asthma (Mukolo \& Heflinger, 2011); (b) stimulant medications are viewed rather contentiously by the general public (Bussing \& Gary, 2001); and (c) much misinformation exists about ADHD (Sage et al., 2017).

Given that this non-treatment-seeking sample of parents reported elevated ADHD symptoms and functional impairments in their child and that greater misunderstanding of ADHD was associated with more negative attitudes towards treatment, future research should consider how best to improve understanding ADHD (e.g., that it is not caused by poor parenting) and knowledge of ADHD medications (e.g., does not increase risk for substance abuse). Further, feeling knowledgeable about a diagnosis helps parents to feel empowered in making treatment decisions (Hummelinck \& Pollock, 2006). Parents often rely upon pediatric primary care providers, books and schools for information regarding ADHD (Sciberras, Iyer, Efron, \& Green, 2010). Thus, these future efforts to increase parental knowledge will likely include collaborating with pediatric primary care providers and school psychologists.

Susceptibility to ADHD Stigma. Fear of stigma is the most commonly cited reason for not accessing mental health treatment in general (Gulliver et al., 2010) and ADHD specifically (Bussing et al., 2012). Fear of stigma is not only a barrier to accessing treatment, but is also a 
contributing factor to parents ceasing evidence-based pharmacological treatment for their children (Ahmed et al., 2013; Kazdin et al., 1997).

Susceptibility to ADHD stigma was associated with lower self-perception and poorer patient-doctor relationships. Parents with higher parenting self-efficacy may be resistant to the negative effects of stigma. While this topic has not been investigated in the ADHD parenting literature, in the non-ADHD literature, stigma resistance and self-efficacy are strongly related (Firmin, Luther, Lysaker, Minor, \& Salyers, 2016).

Parenting self-efficacy has been previously demonstrated to be related to lower acceptability of ADHD medication and the endorsement of behavioral treatment over ADHD medication (Jiang et al., 2014). Parents with higher parenting self-efficacy may feel as if they do not need to rely on medications (Johnston et al., 2010). Relatedly, an outcome of behavioral parent training programs for managing pediatric ADHD is enhanced parenting self-efficacy (Heath, Curtis, Fan, \& McPherson, 2015). Thus, parenting self-efficacy and behavioral treatments for ADHD appear bidirectionally related.

A parental preference for behavioral treatment demonstrated in previous studies (Jiang et al., 2014; Johnston et al., 2010) is not inherently negative. In fact, some data suggest that starting behavioral interventions before medication for ADHD management is associated with greater parental engagement in treatment and lower levels of treatment attrition (Pelham et al., 2016). Future studies should consider how parental self-efficacy and preferences for behavioral treatments in ADHD are associated with attitudes towards medication and how these preferences may change over time.

Finally, with regard to patient-doctor relationships, parents with higher levels of parenting self-efficacy may feel in control of treatment decisions and empowered in interactions 
with their doctors. Psychological empowerment refers to three inter-related dimensions (a) cognitive appraisals of self-efficacy, control, and competence, (b) knowledge and (c) participatory behaviors with others (Perkins \& Zimmerman, 1995). Psychological empowerment has been previously noted to be associated with positive health outcomes (Florian \& Elad, 1998) and more contentment with health related treatment decisions (Davison \& Degner, 1997). Future research should consider the extent to which psychological empowerment helps to explain the relation between low stigma, high self-efficacy and positive patient-doctor relationships.

The critical role of self-efficacy in psychological empowerment, the saliency of stigma as a barrier to treatment, the relationship between higher self-efficacy and lower stigma, and the associations between low susceptibility to stigma and greater self-perception and patient-doctor relationships highlight the need for initiatives to reduce susceptibility to stigma in non-treatmentseeking parents of children with ADHD. Decreasing susceptibility to stigma may lead to greater health outcomes and greater contentment and engagement with treatment decisions, as well as decrease the delay to treatment for children with ADHD.

\section{Hypothesis 1b - The Impact of Previous Provider Relationships on ADHD Treatment}

\section{Attitudes}

In support of hypothesis $1 \mathrm{~b}$, more positive experiences with a child's past treatment provider was significantly associated with lower worries about ADHD medication. Treatmentseeking parents worry about the long-term effects of ADHD medications on their child's development (Berger, Dor, Nevo, \& Goldzweig, 2008; Hansen \& Hansen, 2006). Further, parents prefer doctors who they view as diagnostic experts and provide psychoeducation (Coletti et al., 2012) and having a positive relationship and previous experiences with a child's provider builds trust in the provider (King et al., 2015). 
Conversely, parents' positive experiences with their own provider were associated with increased insight about the need for medication treatment. Others have reported that personal previous successful experiences with treatment is associated with more positive treatment attitudes (Liu et al., 1991). This finding, in a non-treatment-seeking sample, suggests that these associations may exist for those not currently seeking treatment. Having a positive experience with previous treatment providers may engender a better understanding about treatment, its importance, and its safety. When parents had greater satisfaction with their own provider, they may have been more open to learning about ADHD assessment and treatment, feel more empowered to ask questions, or trust doctors as experts (Coletti et al., 2012; Ha \& Longnecker, 2010; Kraetschmer et al., 2004; Vermeire et al., 2001). This, in turn, was related to increased insight about treatment.

Given that parents endorse worries about treatment (Berger et al., 2008) and often revisit their treatment decisions (Brinkman et al., 2009), along with results of the current study, reduction of worries about children's treatment is of clinically significant import. The results of this study demonstrate the possibly critical role of parent-doctor relationships in increasing willingness to try ADHD treatment.

\section{Hypothesis 1c - ADHD Knowledge, Symptom Recognition and Medication Attitudes}

Greater ADHD knowledge was associated significantly with more treatment insight in this non-treatment-seeking sample of parents. This replicates previous findings that individuals who are more knowledgeable about ADHD may have a better understanding about the effectiveness and appropriate use of medications, and thus, hold more positive attitudes towards these treatments (Bennet et al., 1996; Sciutto, 2015). The strong relationship between knowledge and insight about treatment demonstrate a critical avenue for increasing treatment contact. 
Contrary to previous research about symptom recognition and attitudes towards treatment (Mojtabai et al., 2011; Sayal et al., 2006), the ability to recognize symptoms of ADHD as characteristic of ADHD was not related to attitudes towards treatment. This may be due to the fairly high rate of symptom recognition in the sample $(71.4 \%$ correct $)$; previous research on barriers to treatment for other mental health disorders has found lower symptom recognition rates (e.g., $67.3 \%$ of adults are able to recognize symptoms of depression and $36.2 \%$ schizophrenia from similarly structured vignettes) (Jorm, Christensen, \& Griffiths, 2006). The restricted variance in our sample may have reduced our power to detect differences.

In addition to this statistical explanation for these null findings, it is also possible that although these parents could recognize ADHD symptoms, this recognition did not impact attitudes towards treatment. This is consistent with previous research which has suggested despite recognizing the presence of ADHD symptoms, few parents access treatment for their children (Sayal et al., 2006). That ADHD symptom recognition and treatment attitudes were not related may also be a function of the non-treatment-seeking aspect of this sample. Factors not explored in this study (e.g., teacher input, level of spouse concern, etc.) may explain why parents can accurately recognize ADHD symptoms yet this recognition does not predict to treatment attitudes.

\section{Hypotheses 2a-2c, 3 - Predicting Behavior from Attitudes}

Hypotheses about factors that might be significantly associated with time spent on the ADHD information page and seeking additional information about ADHD resources were unsupported. Although attitudes and behaviors are related (Crano \& Prislin, 2011; Sheeran, 2002), there are other factors that affect attitude such as vested interest (i.e., the attitude has noticeable and perceived direct or indirect effects on the individual) (Johnson, Siegel, \& Crano, 
2014). Given that child impairment was not related to time spent on the ADHD information page, and symptoms were only marginally related, parents may not have had a vested interest in the information, although arguably the information could be helpful to them.

Stewart, Pyke-Grimm, and Kelly (2005) propose a model of parental treatment decisionmaking related to pediatric oncology. This model includes decision-making contextual factors and decision-making process factors. In this model, contextual factors include illness factors (e.g., prognosis/severity of illness), person factors (e.g., culture, education level), and relationship factors (e.g., trust in healthcare provider). These contextual factors affect process factors, which include the congruence between one's preferred role in decision making (i.e., passive, collaborative, or active) and one's actual role. These process factors affect decisional outcomes such as decisional conflict and satisfaction with decision (Stewart et al., 2005). This model can broadly be applied to ADHD as well. The current study focused on contextual factors, particularly person and relationship factors. Understanding other decision-making process factors that impact parents of children with ADHD is important, yet unexplored in the current study.

The current study also did not examine illness factors, which may be important contextual factors in decision-making (Stewart et al., 2005). Other models of health-related decision-making also emphasize the importance of perceptions of disorders in decision-making. The health belief model (HBM) is one of the most influential theories for explaining health related behaviors. In this model, individual perceptions of the condition (severity, susceptibility) lead to perceived threat of the condition (Rosenstock, 1990). Perceived threat is moderated by demographic factors, social variables such as perceived peer pressure, knowledge of the condition, and cues to action (e.g., advice from others, having a family member treated for the condition, etc.). These factors predict to the likelihood of action. In this study, ADHD symptom 
recognition levels were fairly high. The majority of parents correctly identified ADHD symptoms as being representative of ADHD. Despite rating their child as having elevated symptoms and impairments, however, these parents may not have perceived ADHD as "serious" or that their child was susceptible, which may have affected the treatment-seeking behavior process (Rosenstock, 1990; Stewart et al., 2005).

In addition, the impact of social influences such as subjective or injunctive norms (Miller \& Prentice, 1996), unexplored in this study, may help to explain the lack of a relation between attitudes and behaviors. Finally, others have suggested that parents prefer to have a dialogue with their pediatric primary care physician about the specific needs of their child rather than receive general educational information about ADHD (Sciberras et al., 2010). Some combination of the above models likely explains why associations between misunderstanding of ADHD, susceptibility to ADHD stigma, previous experiences with providers, and ADHD knowledge and symptom recognition were not predictive of actual behaviors (time spent on the ADHD information page and seeking additional information about ADHD resources).

The lack of an association between knowledge of ADHD and information-seeking behaviors stands in contrast to many public health initiatives for other health conditions (e.g., asthma, autism; note: not ADHD; to our knowledge, there is no public health initiative to increase knowledge of ADHD). Current efforts to increase treatment-seeking behaviors in other health conditions focus on providing information to correct misconceptions, reducing stigma, and increasing knowledge (Perry et al., 2014; Pinfold et al., 2003; Schachter et al., 2008; Spence et al., 2005; Watson et al., 2004; Wyn et al., 2000). The premise of these campaigns is that by increasing knowledge and decreasing stigma (i.e., two well-reported barriers to treatmentseeking for mental health disorders), the delay to treatment will decrease. These present results 
suggest that ADHD may be somewhat different and future attempts to increase informationseeking behaviors should consider why.

\section{Limitations}

There are several limitations to the current study that support the need for further investigation of this topic. First, the sample was mostly White, women, and highly educated. There is therefore need for replication in a more diverse sample to increase generalizability. For example, research on parents of children with ADHD indicates that the majority of parents use the internet for ADHD and ADHD medication information, but that White parents have more access to internet than parents of other races (Sage et al., 2017). Information-seeking behavior thus needs to be addressed in a more socioeconomic and racially diverse sample.

Further examination of fathers and their role in treatment-seeking should also be considered. Fathers, like mothers, have an important role in child and adolescent development (Lamb, 2004; Phares, Lopez, Fields, Kamboukos, \& Duhig, 2005b). Nonetheless, fathers' roles in the treatment, etiology, and course of pediatric mental health disorders is an under-researched and poorly understood topic (Bögels \& Phares, 2008; Lamb, 2004; Phares, Fields, Kamboukos, \& Lopez, 2005a; Phares et al., 2005b). A review of the literature of fathers in chronic medical conditions suggests that compared to mothers, fathers use fewer coping strategies, exhibit more psychological symptoms in response to a child's chronic condition and provide lower levels of encouragement to their daughters (Phares et al., 2005b). Relatedly, there is a need to understand what differential opinions, effects, and responsibilities, if any, exist in the treatment-seeking roles of fathers and mothers for their child's ADHD. Replication and extension of the current study in a more balanced sample may provide more insight into what differences in attitudes and 
behaviors may occur between mothers and fathers and how these differences and interactions may affect a child's access to evidence-based treatment.

Although there was evidence for significant associations between hypothesized factors and treatment attitudes, there was still significant variance unaccounted for in the models. The transtheoretical model cites six stages of change (e.g., treatment-seeking behaviors) including precontemplation, contemplation, preparation, action, maintenance, and termination (Prochaska \& Velicer, 1997). Individuals who never, or delay to, seek treatment may stagnate in one of these first three stages (i.e., precontemplation, contemplation, preparation). Although not explicitly measured, given the non-treatment-seeking nature of the sample, parents were likely in the precontemplative, contemplative, or preparation stage of change.

As suggested by the transtheoretical model, stage of readiness to change may affect what factors are most salient for an individual (Prochaska \& Velicer, 1997). Stage-matched interventions may be most beneficial for reaching at-risk populations (Prochaska \& Velicer, 1997). Undoubtedly, there is still need to examine significant predictors of treatment attitudes beyond what the current study considered and stage of readiness to change likely represents one of these predictors. There is also need for longitudinal work to understand the dynamic nature of treatment attitudes and behaviors over time. Future research should consider how stage of change affects treatment attitudes (and vice versa). The current child sample was symptomatic, yet untreated and therefore, considering how parental attitudes, and ultimately decisions, may change across stages of change may enable a better understanding of parents' treatment attitudes. Better understanding this variance may lead to the development of more targeted intervention efforts towards increasing children's access to evidence-based treatment. 
This study also may have been low in ecological validity. Participants may not have responded or behaved the same way they would in real life. There were possible demand characteristics (e.g., social desirability) that may have affected results. However, given the anonymous nature of the survey (i.e., conducted in the privacy of their own homes) participants may have been more resistant to these effects. Further, participants may have been motivated to simply complete the study, rather than seek additional information, and therefore did not seek additional information (mock webpage presented at the end of the survey), despite having some interest in the topic. The current study measured time spent on the information page as well as seeking more information about treatment resources Attention to, and comprehension of, the ADHD information was not recorded. On the other hand, it is possible that the survey primed individuals to be concerned about ADHD. The measures were presented in the same order to every participant to ensure adequate completion of critical variables (e.g., demographics), but this may have led to unintended effects of seeking additional information despite having low interest. However, given the low rate of desire for more information, this seems unlikely. Information-seeking behavior was chosen as a measure of treatment-seeking behavior due to the importance of knowledge as a facilitator to treatment (Bennet et al., 1996; Sciutto, 2015). Additionally, evidence that suggests that parents of children with ADHD rely on (often inaccurate) online information to answer their questions about their child's ADHD (Sage et al., 2017). Furthermore, measures used in previous studies (e.g., What types of websites do you used to gather information [about ADHD]?) (Sage et al., 2017) may not be as relevant to nontreatment-seeking parents as they may not be gathering information about ADHD. By presenting parents with factual information about ADHD and ADHD treatment, while recording time spent on the mock webpage and also providing opportunity to learn more about resources, the current 
study was able to objectively measure one aspect of information-seeking that was not related to parents' past behaviors. However, information-seeking certainly does not encompass or represent all types of treatment-seeking-relevant behaviors. Other behaviors, such as decision to take an ADHD screener if prompted, set up appointments with assessment providers, and reactions to treatment provider-initiated conversations about ADHD assessment may also be important behaviors to understand. Further investigation of these behaviors, as well as how they may relate to treatment contact, is likely important.

The QATT (Ferrin et al., 2012), which was used as a main outcome measure in the current study, demonstrated low internal consistency in this sample. Although this measure has been well validated in treatment-seeking populations, this measure has not been used in nontreatment-seeking samples. Low internal consistency in this sample may indicate that validated factors that emerged in a treatment-seeking sample (Ferrin et al., 2012), may not be representative of unitary constructs in a non-treatment-seeking sample. Validation of the QATT in a non-treatment-seeking sample, following similar procedures to the validation methods described by Ferrin et al. (2012) and confirmatory and exploratory factor analyses may shed light on possibly different factors of treatment analyses.

Further, the QATT may characterize some, but not all, relevant treatment attitudes in a non-treatment-seeking sample. Therefore, there may be reason for future research to validate or develop additional measures of treatment attitudes in non-treatment-seeking samples. For example, the QATT primarily focuses on internally-focused treatment attitudes (e.g., "I am worried about taking this medication"), but externally-focused treatment attitudes (e.g., "Parents who use ADHD medications are lazy") may also be salient as barriers to treatment for non- 
treatment-seeking parents. Future validation and examination of treatment attitudes in this population is likely important to understanding treatment attitudes.

\section{Directions for Future Research and Implications for Clinical Practice}

The current study began the process of unraveling the complicated nature of barriers to treatment through understanding treatment attitudes and information-seeking behaviors in a nontreatment-seeking sample of parents. There are a variety of future directions for this area in addition to those noted above particularly in light of the large associations between susceptibility to ADHD stigma and self-perceptions and patient-doctor relationships, satisfaction with a child's past provider and worries about treatment, and knowledge and insight into the need for treatment. These three areas represent the strongest associations in the current study, highlighting possible areas for focus in interventions to reduce barriers to treatment among these three different factors of treatment attitudes.

Currently, campaigns that aim to increase knowledge and decrease barriers to treatment are reliant on providing information (Perry et al., 2014; Pinfold et al., 2003; Schachter et al., 2008; Spence et al., 2005; Watson et al., 2004; Wyn et al., 2000). Given the results of the current study that low knowledge, high misunderstandings of ADHD, and susceptibility to stigma are all related to more negative treatment attitudes, and particularly that knowledge was robustly related to insight about the need for treatment, the provision of information seems a logical way to try to change treatment attitudes. However, campaigns that market themselves as providing more information may not reach their target audiences. The results of the current study suggest that those who may benefit from these campaigns (i.e., those with lower levels of knowledge and understanding about ADHD and ADHD treatments and higher levels of stigma) were no more likely to be receptive to or seek addition information than those with higher levels of knowledge. 
Thus, more targeted interventions may be beneficial to consider. In the current study, parents whom rated their child as more impaired sought more information about ADHD resources than parents whom did not desire more information. Nonetheless, the amount of time parents spent on the ADHD information page was not related to their ratings of their child's functional impairment. The results of this study suggest there was a wide range of time spent on the ADHD information page, yet this range was not explained by parents' views of their child as being impaired. It is possible that parents may not view their child as more impaired or symptomatic compared to the average child, thus they were unaware that resources may have been of benefit. If neither child impairment nor low knowledge is related to parents spending time on the ADHD information page, currently existing efforts to increase access to evidencebased treatment may need to be reconsidered.

The current study measured one aspect of treatment-seeking behavior (i.e., informationseeking). There are a variety of other relevant treatment-seeking behaviors that future research should consider. For example, parents' acceptance and response to treatment provider inquiries related to providing psychoeducation about ADHD or other mental health / neurodevelopmental disorders, response to campaigns to reduce barriers to mental health treatments, willingness to take a screening tool for ADHD or other neurodevelopmental / mental health disorders, willingness to schedule an appointment with a treatment provider in response to results on a screener, and other treatment-seeking behaviors may all be relevant and clinically important to examine.

A significant body of work to increase evidence-based ADHD diagnosis and treatment focuses not on parents, but rather upon increasing pediatrician and primary care providers' evidence-based practice (Carroll et al., 2013; Co et al., 2010; Epstein et al., 2016; Epstein et al., 
2011; Epstein et al., 2008; Epstein et al., 2007; Geltman et al., 2015; Lavigne et al., 2011; Olson, Rosenbaum, Dosa, \& Roizen, 2005). Although some of this work does aim to increase shared decision-making (Brinkman et al., 2013), a majority of these interventions focus on how to increase pediatric primary care provider ADHD assessment and treatment monitoring practices to be in line with American Academy of Pediatrics $(A A P)$ practice parameters. Given the low rate of adherence to evidence-based practice guidelines for primary care providers (e.g., $4 \%$ adherence to $A A P$ guidelines) (Olson et al., 2005) and the critical role that primary care providers play in access to evidence-based treatment (Martini et al., 2012), this line of research is important. However, in light of the current findings, these pediatric primary care interventions may benefit from increased emphasis on teaching primary care providers about the many and varied barriers to treatment, factors associated with attitudes, and specific practices that might increase parents' willingness to seek resources. For example, these programs may highlight not only the provision of psychoeducation, but also the importance of addressing past provider experience and maintaining a strong patient-doctor relationship (Coletti et al., 2012; Ha \& Longnecker, 2010; Kraetschmer et al., 2004; Vermeire et al., 2001).

Evidence that lower susceptibility to stigma is related to more positive treatment attitudes highlights the need for additional attention in this area. Efforts to decrease ADHD stigma and increase parenting self-efficacy may increase perceptions that ADHD treatment-seeking is a socially acceptable behavior. Moreover, previous research in other clinical samples suggests that perceived stigma is related to both lower self-efficacy and poorer coping with a disorder (Kleim et al., 2008). Accordingly, decreasing stigma and fostering self-efficacy may be important both for increasing treatment-seeking, but also for increasing one's ability and resilience to the symptoms and negative effects of having a child with a mental health disorder. Treatment 
providers should be mindful of assessing and addressing parenting self-efficacy as well as ADHD stigma. Existing questionnaires and surveys exist, including the parenting self-efficacy scale (Suzuki et al., 2009), the ASQ (Kellison et al., 2010), and QATT (Ferrin et al., 2012) used in the current study. Information from these questionnaires may increase pediatric treatment providers understanding of which barriers may be most salient for their patients and patients' parents. Integration of education about the effectiveness and safety of medication, when appropriate, as well as attempts to increase parental resistance to stigma may both be important in increasing treatment-seeking behaviors.

While increasing effective psychoeducation and resistance to stigma is likely important, the results of the current study suggest that although these aspects are important to treatment attitudes, actual information-seeking behavior may be influenced by other variables and motivations. Ryan and Deci (2000) highlight the importance of applying self-determination theory (Ryan, Kuhl, \& Deci, 1997) towards enhancing treatment-seeking and treatment engagement. Given the findings of the current study, inclusion of basic principles of selfdetermination theory, such as reinforcing autonomy and increasing motivation, may be fruitful towards increasing parents' treatment-related behaviors.

Finally, treatment providers should be aware of the effects of past treatment providers on parents' treatment attitudes. Exploration of these past experiences may help build patient-doctor relationships and increase positive treatment attitudes. A simple inclusion of this question in intake or assessment paperwork may help treatment providers better understand how parents may feel about treatment providers in general and thus parents' treatment attitudes. Given parents ratings of the importance of thorough psychoeducation (Coletti et al., 2012) and effective doctor communication (Ha \& Longnecker, 2010), the possible importance of congruence between 
parents' actual and desired role in the decision-making process (Stewart et al., 2005), the large associations between susceptibility to ADHD stigma and self-perception / patient-doctor relationship and between satisfaction with a child's past providers and worries about treatments, treatment providers may wish to include more time spent discussing not only ADHD and treatment, but also focusing on relationship building, discussion / clarification of preferred and necessary parent-doctor roles, and building resistance to stigma.

\section{Conclusions}

Childhood ADHD is a common and impairing neurodevelopmental disorder with longterm negative outcomes in a variety of domains (Barkley et al., 2006; Molina et al., 2009). Despite the prevalence of safe and effective treatments for ADHD (Faraone, 2003; Faraone \& Buitelaar, 2010; Shaw et al., 2012), there is a significant delay to treatment and a low rate of lifetime treatment contact for individuals with ADHD (Dakwar et al., 2014). There are a wide variety of barriers to treatment such as misconceptions about ADHD and uncertainty of where to go for help (Bussing et al., 2003; Partridge et al., 2014).

Most research on barriers to treatment for ADHD have focused either on hypothetical case vignettes (i.e., unrelated to one's own child) or samples of parents who have already made the decision to seek treatment. The current study examined a non-treatment-seeking sample to determine what barriers to treatment may be salient to those who have not yet, or may never, seek treatment for ADHD. Consistent with previous research, the current study found that knowledge and understanding about ADHD and ADHD treatments (Partridge et al., 2012, 2014; Sciutto, 2015), resistance to stigma (Ahmed et al., 2013; Johnston et al., 2008), and positive experience with past providers (Liu et al., 1991) were significantly related to positive attitudes about treatment. Nonetheless, despite finding significant associations between hypothesized 
factors and treatment attitudes, models assessing relations with information-seeking behavior were non-significant.

Additional research on factors associated with treatment attitudes as well as continued attention to development and assessment of efforts to increase treatment attitudes is warranted. Future research should continue to explore how poor understanding of ADHD, stigma about ADHD, low parenting self-efficacy and previous relationships with providers predict to not just treatment attitudes, but also treatment behaviors. As the current study highlighted, investigation of barriers is important to consider in a non-treatment-seeking sample, given the prevalence of ADHD symptoms and impairment demonstrated in children whose parents who are not currently accessing evidence-based treatment 
Figure 1

Hypotheses and Data Analysis of the Current Study

\begin{tabular}{|c|c|c|c|}
\hline Hypothesis & Independent Variables & Analyses & Hypotheses \\
\hline 1a & $\begin{array}{l}\text { Perceptions of symptoms as externally } \\
\text { controlled, parental self-efficacy, stigma, } \\
\text { and misconceptions }\end{array}$ & $\begin{array}{l}\text { Exploratory PCA } \\
\text { Linear regression }\end{array}$ & $\begin{array}{l}\text { Associated with negative treatment attitudes } \\
\text { (QATT) }\end{array}$ \\
\hline $1 b$ & $\begin{array}{l}\text { Greater satisfaction with past treatment } \\
\text { provider for self or child }\end{array}$ & Linear regression & $\begin{array}{l}\text { Associated with positive treatment attitudes } \\
\text { (QATT) }\end{array}$ \\
\hline $1 \mathrm{c}$ & Symptom recognition and knowledge & Linear regression & $\begin{array}{l}\text { Associated with positive treatment attitudes } \\
\text { (QATT) }\end{array}$ \\
\hline $2 \mathrm{a}$ & $\begin{array}{l}\text { Misconceptions and stigma } \\
\text { Self-efficacy, externally controlled } \\
\text { symptoms }\end{array}$ & $\begin{array}{l}\text { Linear regression } \\
\text { Logistic regression }\end{array}$ & $\begin{array}{l}\text { Negatively associated with information- } \\
\text { seeking behavior } \\
\text { Positively associated with information- } \\
\text { seeking behavior }\end{array}$ \\
\hline $2 b$ & $\begin{array}{l}\text { Greater satisfaction with past treatment } \\
\text { provider for self or child }\end{array}$ & $\begin{array}{l}\text { Linear regression } \\
\text { Logistic regression }\end{array}$ & $\begin{array}{l}\text { Positively associated with information- } \\
\text { seeking behavior }\end{array}$ \\
\hline $2 \mathrm{c}$ & Symptom recognition and knowledge & $\begin{array}{l}\text { Linear regression } \\
\text { Logistic regression }\end{array}$ & $\begin{array}{l}\text { Positively associated with information- } \\
\text { seeking behavior }\end{array}$ \\
\hline 3 & Positive treatment attitudes & $\begin{array}{l}\text { Linear regression } \\
\text { Logistic regression }\end{array}$ & $\begin{array}{l}\text { Positively associated with information- } \\
\text { seeking behavior }\end{array}$ \\
\hline
\end{tabular}

Note. QATT $=$ Questionnaire about Attitudes Towards Treatment

$\mathrm{PCA}=$ Principal Components Analysis 
Table 1

Demographic, Predictor, and Outcome Variables

\begin{tabular}{|c|c|c|c|c|c|c|c|c|c|}
\hline & $\begin{array}{c}\text { Camp } \\
(N=\mathbf{3 6})\end{array}$ & & $\begin{array}{c}\text { mTurk } \\
(N=133)\end{array}$ & & & & & $\begin{array}{c}\text { Total } \\
(N=169)\end{array}$ & \\
\hline Variable & $M(S D)$ & $\%$ & $M(S D)$ & $\%$ & $\boldsymbol{F}$ & $\eta^{2}$ & $x^{2}$ & $M(S D)$ & $\%$ \\
\hline Age & $\begin{array}{l}42.44 \\
(6.93)\end{array}$ & & $\begin{array}{l}39.41 \\
(9.62)\end{array}$ & & 2.98 & .01 & & $\begin{array}{l}40.00 \\
(9.22)\end{array}$ & \\
\hline Gender & & $\begin{array}{l}2.80 \% \\
\text { Men }\end{array}$ & & $\begin{array}{l}33.10 \% \\
\text { Men }\end{array}$ & & & $13.32 * * *$ & & $26.60 \%$ Men \\
\hline Race & & $\begin{array}{l}100.00 \% \\
\text { White }\end{array}$ & & $\begin{array}{l}91.00 \% \\
\text { White }\end{array}$ & & & 0.39 & & 92.90\% White \\
\hline Education & & $\begin{array}{c}92.20 \% \\
\text { Some } \\
\text { College } \\
\text { Education }\end{array}$ & & $\begin{array}{c}82.70 \% \\
\text { Some } \\
\text { College } \\
\text { Education }\end{array}$ & & & $6.54 * *$ & & $\begin{array}{c}85.80 \% \text { Some } \\
\text { College } \\
\text { Education }\end{array}$ \\
\hline $\begin{array}{l}\text { Parent Number of } \\
\text { Mental Illnesses }\end{array}$ & $\begin{array}{c}0.28 \\
(0.68)\end{array}$ & & $\begin{array}{c}0.48 \\
(0.75)\end{array}$ & & 2.12 & .007 & & $\begin{array}{c}0.44 \\
(0.74)\end{array}$ & \\
\hline Parent ADHD & $\begin{array}{c}96.88 \% \\
\text { no }\end{array}$ & & $\begin{array}{c}96.90 \% \\
\text { no }\end{array}$ & & & & & & $96.89 \%$ no \\
\hline PHQ Anxiety & $\begin{array}{c}3.13 \\
(1.65)\end{array}$ & & $\begin{array}{l}3.28 \\
(1.57)\end{array}$ & & 0.28 & .001 & & $\begin{array}{c}3.25 \\
(1.59)\end{array}$ & \\
\hline PHQ Depression & $\begin{array}{c}2.55 \\
(1.18)\end{array}$ & & $\begin{array}{l}3.03 \\
(1.40)\end{array}$ & & 3.89 & .01 & & $\begin{array}{c}2.93 \\
(1.37)\end{array}$ & \\
\hline
\end{tabular}




\begin{tabular}{|c|c|c|c|c|c|c|c|c|c|}
\hline ASRS & $\begin{array}{c}7.53 \\
(3.68)\end{array}$ & & $\begin{array}{c}7.55 \\
(4.82)\end{array}$ & & 0.00 & .000 & & $\begin{array}{c}7.54 \\
(4.59)\end{array}$ & \\
\hline $\begin{array}{c}\text { Ratings of } \\
\text { Satisfaction with } \\
\text { Any Adult } \\
\text { Treatment } \\
\text { Provider }\end{array}$ & $\begin{array}{l}4.08 \\
(0.60)\end{array}$ & & $\begin{array}{c}3.68 \\
(0.79)\end{array}$ & & $8.55^{* *}$ & .03 & & $\begin{array}{c}3.77 \\
(0.77)\end{array}$ & \\
\hline $\begin{array}{l}\text { Number of } \\
\text { Children }\end{array}$ & $\begin{array}{c}2.06 \\
(0.67)\end{array}$ & & $\begin{array}{c}2.05 \\
(1.08)\end{array}$ & & 0.00 & .000 & & $\begin{array}{c}2.05 \\
(1.00)\end{array}$ & \\
\hline Child Age & $\begin{array}{l}10.14 \\
(4.23)\end{array}$ & & $\begin{array}{l}10.03 \\
(8.94)\end{array}$ & & 0.01 & .000 & & $\begin{array}{l}10.06 \\
(8.18)\end{array}$ & \\
\hline Child Gender & & $\begin{array}{c}44.40 \% \\
\text { Boys }\end{array}$ & & $\begin{array}{c}49.60 \% \\
\text { Boys }\end{array}$ & & & 0.350 & & $48.5 \%$ Boys \\
\hline $\begin{array}{c}\text { ADHD-RS-5 } \\
\text { Total } \\
\text { Percentile }\end{array}$ & $\begin{array}{c}68.64 \\
(28.37)\end{array}$ & & $\begin{array}{c}71.79 \\
(28.11)\end{array}$ & & .35 & .002 & & $\begin{array}{c}71.11 \\
(28.11)\end{array}$ & \\
\hline $\begin{array}{l}\text { ADHD-RS-5 } \\
\text { Hyperactivity } \\
\text { Percentile }\end{array}$ & $\begin{array}{c}70.36 \\
(23.66)\end{array}$ & & $\begin{array}{c}72.63 \\
(26.89)\end{array}$ & & .44 & .003 & & $\begin{array}{c}72.94 \\
(26.20)\end{array}$ & \\
\hline $\begin{array}{l}\text { ADHD-RS-5 } \\
\text { Inattention } \\
\text { Percentile }\end{array}$ & $\begin{array}{c}63.67 \\
(28.74)\end{array}$ & & $\begin{array}{c}69.21 \\
(28.37)\end{array}$ & & 1.08 & .006 & & $\begin{array}{c}68.03 \\
(28.45)\end{array}$ & \\
\hline
\end{tabular}




\begin{tabular}{|c|c|c|c|c|c|}
\hline $\begin{array}{c}\text { Global } \\
\text { Impairment on } \\
\text { IRS }\end{array}$ & $\begin{array}{l}1.61 \\
(1.71)\end{array}$ & $\begin{array}{c}1.62 \\
(1.67)\end{array}$ & 0.00 & .000 & $\begin{array}{c}1.62 \\
(1.68)\end{array}$ \\
\hline $\begin{array}{c}\text { Ratings of } \\
\text { Satisfaction with } \\
\text { Any Child } \\
\text { Treatment } \\
\text { Provider }\end{array}$ & $\begin{array}{c}4.22 \\
(0.44)\end{array}$ & $\begin{array}{c}3.81 \\
(0.89)\end{array}$ & $6.95 * *$ & .02 & $\begin{array}{c}3.90 \\
(0.86)\end{array}$ \\
\hline $\begin{array}{l}\text { Perceptions of } \\
\text { ADHD as } \\
\text { externally } \\
\text { controlled }\end{array}$ & $\begin{array}{c}0.43 \\
(0.44)\end{array}$ & $\begin{array}{c}0.46 \\
(0.54)\end{array}$ & 0.10 & .000 & $\begin{array}{c}0.46 \\
(0.52)\end{array}$ \\
\hline Knowledge & $\begin{array}{l}19.12 \\
(2.79)\end{array}$ & $\begin{array}{l}18.52 \\
(2.78)\end{array}$ & 1.49 & .005 & $\begin{array}{l}18.65 \\
(2.79)\end{array}$ \\
\hline Misconceptions & $\begin{array}{c}6.88 \\
(2.79)\end{array}$ & $\begin{array}{c}7.48 \\
(2.78)\end{array}$ & 1.49 & .005 & $\begin{array}{c}7.35 \\
(2.79)\end{array}$ \\
\hline $\begin{array}{l}\text { Parenting Self- } \\
\text { Efficacy }\end{array}$ & $\begin{array}{l}134.26 \\
(12.16)\end{array}$ & $\begin{array}{l}132.30 \\
(13.53)\end{array}$ & 0.69 & .002 & $\begin{array}{l}132.72 \\
(13.24)\end{array}$ \\
\hline $\begin{array}{c}\text { ASQ Total } \\
\text { Stigma }\end{array}$ & $\begin{array}{c}53.62 \\
(12.38)\end{array}$ & $\begin{array}{c}50.57 \\
(15.87)\end{array}$ & 1.24 & .004 & $\begin{array}{c}51.22 \\
(15.21)\end{array}$ \\
\hline QATT Total & $\begin{array}{l}70.27 \\
(9.01)\end{array}$ & $\begin{array}{c}68.63 \\
(10.11)\end{array}$ & 0.89 & .003 & $\begin{array}{l}68.98 \\
(9.88)\end{array}$ \\
\hline
\end{tabular}




\begin{tabular}{|c|c|c|c|c|c|c|c|c|c|}
\hline $\begin{array}{l}\text { QATT Worries } \\
\text { about Medication }\end{array}$ & $\begin{array}{l}11.00 \\
(3.06)\end{array}$ & & $\begin{array}{l}12.03 \\
(4.05)\end{array}$ & & 2.13 & .007 & & $\begin{array}{l}11.81 \\
(3.87)\end{array}$ & \\
\hline $\begin{array}{l}\text { QATT Insight } \\
\text { about Medication }\end{array}$ & $\begin{array}{l}12.36 \\
(4.18)\end{array}$ & & $\begin{array}{l}11.70 \\
(4.54)\end{array}$ & & 0.69 & .002 & & $\begin{array}{l}11.84 \\
(4.46)\end{array}$ & \\
\hline $\begin{array}{l}\text { QATT Self- } \\
\text { Perception and } \\
\text { Patient-Doctor } \\
\text { Relationship }\end{array}$ & $\begin{array}{c}8.82 \\
(2.09)\end{array}$ & & $\begin{array}{l}8.13 \\
(2.26)\end{array}$ & & 3.06 & .01 & & $\begin{array}{l}8.27 \\
(2.24)\end{array}$ & \\
\hline $\begin{array}{l}\text { ADHD Symptom } \\
\text { Recognition }\end{array}$ & & $\begin{array}{l}71.43 \% \\
\text { correct }\end{array}$ & & $\begin{array}{l}71.43 \% \\
\text { correct }\end{array}$ & & & 0.17 & & $71.43 \%$ correc \\
\hline $\begin{array}{l}\text { Time Spent on } \\
\text { ADHD } \\
\text { Information Page } \\
\text { (Seconds) }\end{array}$ & $\begin{array}{c}20.57 \\
(23.18)\end{array}$ & & $\begin{array}{c}24.15 \\
(27.95)\end{array}$ & & 0.85 & .003 & & $\begin{array}{c}23.45 \\
(27.06)\end{array}$ & \\
\hline $\begin{array}{l}\text { Requested more } \\
\text { Information }\end{array}$ & & $\begin{array}{l}5.60 \% \\
\text { Yes }\end{array}$ & & $\begin{array}{c}12.80 \% \\
\text { Yes }\end{array}$ & & & 0.86 & & $11.20 \% \mathrm{Yes}$ \\
\hline
\end{tabular}

Note. $\mathrm{PHQ}=$ Patient Health Questionnaire ASRS = Adult ADHD Self-Report Scale

IRS = Impairment Rating Scale

ADHD-RS-5 $=$ The 5th Edition ADHD Rating Scale

ASQ $=$ Attention Deficit Hyperactivity Disorder (ADHD) Stigma Questionnaire

QATT $=$ Questionnaire about Attitudes Towards Treatment

$* p<0.05, * * p<0.01, * * * p<0.001$ 
Table 2

Correlation Matrix of Outcome Variables

\begin{tabular}{|c|c|c|c|c|c|c|c|c|c|c|}
\hline Variable & $\begin{array}{l}\text { Misunder- } \\
\text { standing of } \\
\text { ADHD }\end{array}$ & $\begin{array}{l}\text { Suscept- } \\
\text { ibility to } \\
\text { ADHD } \\
\text { Stigma }\end{array}$ & $\begin{array}{l}\text { Satisfaction } \\
\text { with Own } \\
\text { Provider }\end{array}$ & $\begin{array}{l}\text { Satisfaction } \\
\text { with Child's } \\
\text { Provider }\end{array}$ & $\begin{array}{l}\text { Knowledge } \\
\text { about } \\
\text { ADHD }\end{array}$ & $\begin{array}{l}\text { ADHD } \\
\text { Symptom } \\
\text { Recogni- } \\
\text { tion }\end{array}$ & $\begin{array}{l}\text { Worries } \\
\text { about Treat- } \\
\text { ment }\end{array}$ & $\begin{array}{l}\quad \text { Hypot } \\
\text { Insight } \\
\text { about } \\
\text { Treat- } \\
\text { ment }\end{array}$ & $\begin{array}{l}\text { sis } 3 \\
\text { Self- } \\
\text { Perception } \\
\text { and Patient- } \\
\text { Doctor } \\
\text { Relation- } \\
\text { ship }\end{array}$ & Total \\
\hline $\begin{array}{l}\text { Misunder- } \\
\text { standing of } \\
\text { ADHD }\end{array}$ & 1.00 & .02 & $-.21 * *$ & $-.18^{*}$ & $-.80 * *$ & $-.47 * *$ & $.25 * *$ & $-.25 * *$ & .003 & .12 \\
\hline $\begin{array}{l}\text { Suscepti- } \\
\text { bility to } \\
\text { ADHD } \\
\text { Stigma }\end{array}$ & & 1.00 & -.03 & -.10 & .09 & .06 & .08 & .13 & $-.38 * *$ & .11 \\
\hline $\begin{array}{l}\text { Satisfaction } \\
\text { with Own } \\
\text { Provider }\end{array}$ & & & 1.00 & $.61 * *$ & $.23 * *$ & .15 & $-.33 * *$ & $.26^{* *}$ & .15 & -.04 \\
\hline $\begin{array}{l}\text { Satisfaction } \\
\text { with } \\
\text { Child's } \\
\text { Provider }\end{array}$ & & & & 1.00 & $.16^{*}$ & $.16^{*}$ & $-.37 * *$ & $.19 *$ & $.15^{*}$ & -.08 \\
\hline $\begin{array}{l}\text { Knowledge } \\
\text { about } \\
\text { ADHD }\end{array}$ & & & & & 1.00 & $.43 * *$ & $-.21 * *$ & $.35^{* *}$ & .025 & -.06 \\
\hline
\end{tabular}




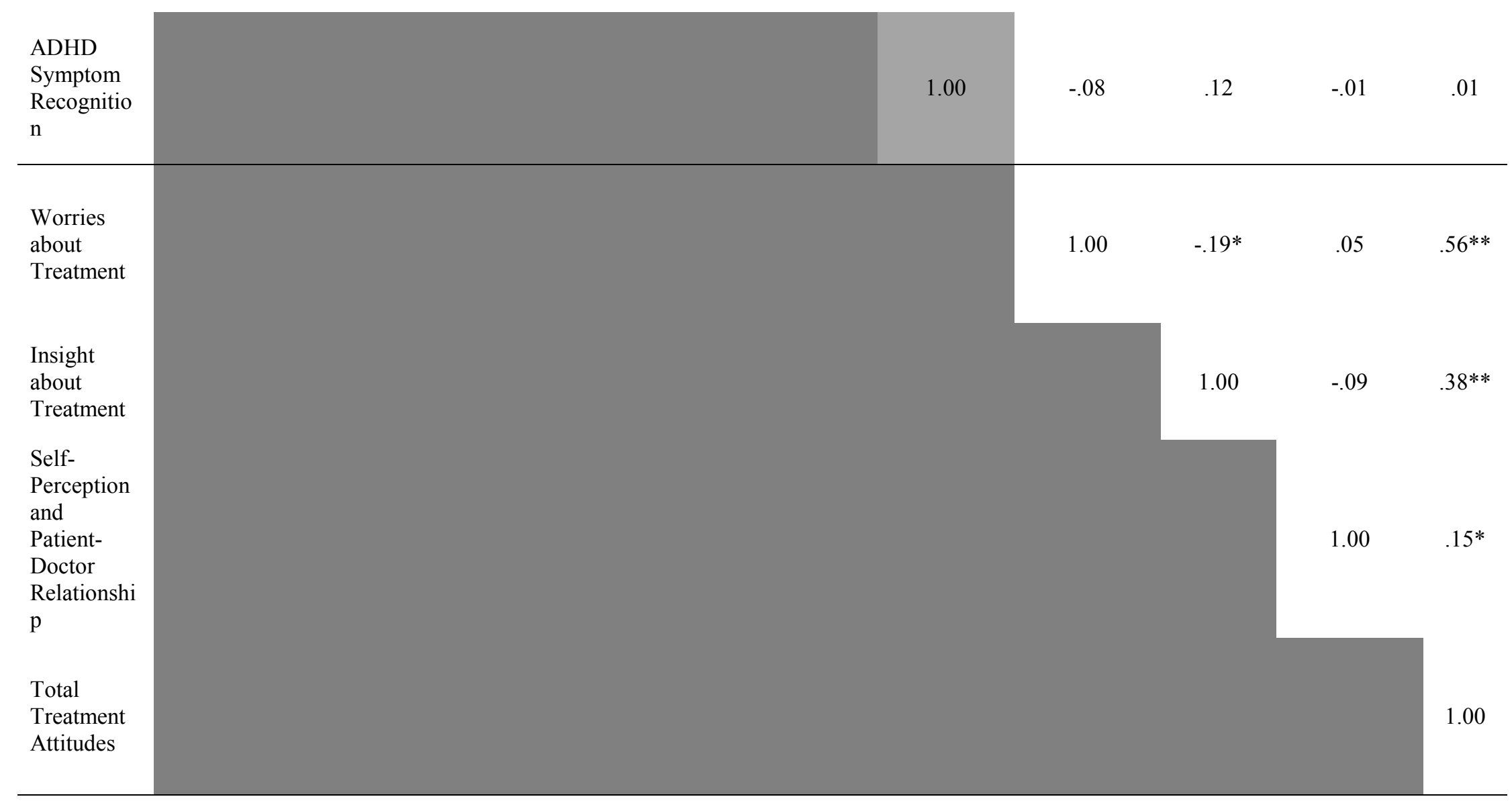

Note: $* \mathrm{p}<0.05,{ }^{* *} \mathrm{p}<0.01,{ }^{* * *} \mathrm{p}<0.001$ 
Table 3.

Component Loadings and Communalities for the SBAKS Misconceptions, Perceptions of ADHD as Externally Controlled, ADHD Stigma, and Parenting Self-Efficacy

\begin{tabular}{lcc}
\hline & \multicolumn{2}{c}{ Component } \\
\hline & $\begin{array}{c}\text { Misunderstanding } \\
\text { of ADHD } \\
1\end{array}$ & $\begin{array}{c}\text { Susceptibility to } \\
\text { ADHD Stigma }\end{array}$ \\
$\begin{array}{l}\text { CAS External } \\
\text { Attributions }\end{array}$ & $\mathbf{0 . 7 6}$ & 2 \\
$\begin{array}{l}\text { SBAKS } \\
\text { Misconceptions }\end{array}$ & $\mathbf{0 . 8 0}$ & 0.22 \\
$\begin{array}{l}\text { ADHD Stigma } \\
\text { Parenting Self- } \\
\text { Efficacy }\end{array}$ & 0.29 & -0.11 \\
\hline
\end{tabular}

Note. CAS $=$ Causal Attributions Scale

SBAKS = Strength in Beliefs about ADHD Scale

Principal Components Analysis with Varimax Rotation 
Table 4

Results of Linear Regressions

\begin{tabular}{|c|c|c|c|c|c|c|c|c|c|}
\hline Hypothesis & Variable & & $\beta$ & $t$ & $R$ & $R^{2}$ & $F$ & $p$ & VIF \\
\hline \multirow{11}{*}{$1 \mathrm{a}$} & \multirow{4}{*}{$\begin{array}{l}\text { QATT } \\
\text { Total }\end{array}$} & Model & & & .16 & .03 & 2.25 & .11 & \\
\hline & & $\begin{array}{l}\text { Misunderstanding } \\
\text { of ADHD }\end{array}$ & .12 & 1.54 & & & & .13 & 1.00 \\
\hline & & $\begin{array}{l}\text { Susceptibility to } \\
\text { ADHD Stigma }\end{array}$ & .11 & 1.43 & & & & .17 & 1.00 \\
\hline & & Model & & & .26 & .07 & 6.06 & .003 & \\
\hline & \multirow[t]{2}{*}{$\begin{array}{l}\text { QATT } \\
\text { Worries }\end{array}$} & $\begin{array}{l}\text { Misunderstanding } \\
\text { of ADHD }\end{array}$ & .25 & 3.30 & & & & .001 & 1.00 \\
\hline & & $\begin{array}{l}\text { Susceptibility to } \\
\text { ADHD Stigma }\end{array}$ & .08 & 1.05 & .29 & & & .15 & 1.00 \\
\hline & & Model & & & .29 & .08 & 7.38 & .001 & \\
\hline & \multirow[t]{2}{*}{$\begin{array}{l}\text { QATT } \\
\text { Insight }\end{array}$} & $\begin{array}{l}\text { Misunderstanding } \\
\text { of ADHD }\end{array}$ & -.25 & -3.39 & & & & .001 & 1.00 \\
\hline & & $\begin{array}{l}\text { Susceptibility to } \\
\text { ADHD Stigma }\end{array}$ & .14 & 1.87 & & & & .06 & 1.00 \\
\hline & OATT & Model & & & .38 & .15 & 14.23 & .000 & \\
\hline & $\begin{array}{l}\text { Self- } \\
\text { perception } \\
\text { and } \\
\text { Patient- } \\
\text { Doctor }\end{array}$ & $\begin{array}{l}\text { Misunderstanding } \\
\text { of ADHD }\end{array}$ & .01 & -5.35 & & & & .89 & 1.00 \\
\hline
\end{tabular}




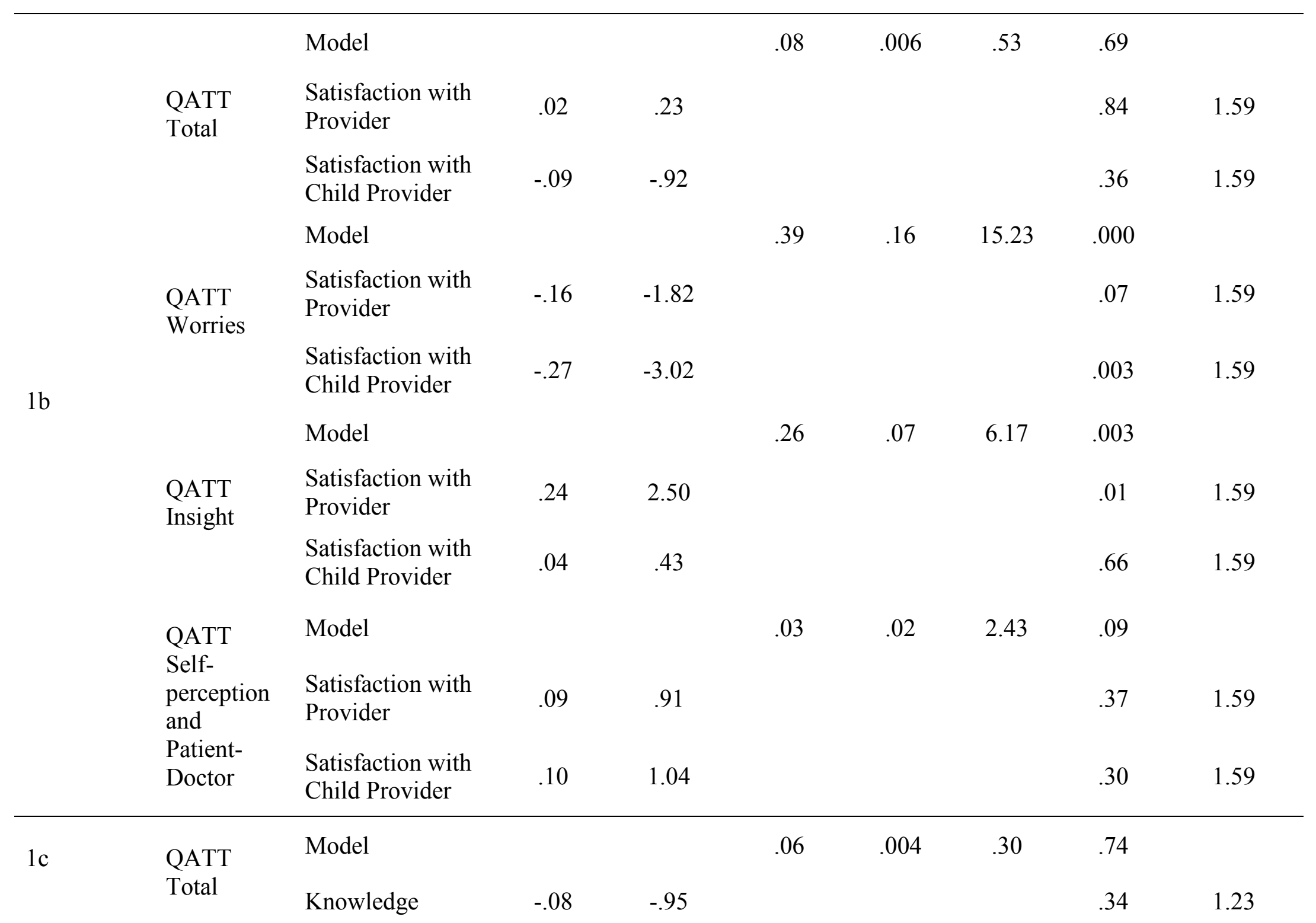




\begin{tabular}{|c|c|c|c|c|c|c|c|c|c|}
\hline & & $\begin{array}{l}\text { Symptom } \\
\text { Recognition }\end{array}$ & .05 & .60 & & & & .55 & 1.23 \\
\hline & \multirow{4}{*}{$\begin{array}{l}\text { QATT } \\
\text { Worries }\end{array}$} & Model & & & .21 & .05 & 3.98 & .02 & \\
\hline & & Knowledge & -.22 & -2.63 & & & & .01 & 1.23 \\
\hline & & $\begin{array}{l}\text { Symptom } \\
\text { Recognition }\end{array}$ & .02 & .23 & & & & .82 & 1.23 \\
\hline & & Model & & & .35 & .12 & 11.40 & .000 & \\
\hline & \multirow{2}{*}{$\begin{array}{l}\text { QATT } \\
\text { Insight }\end{array}$} & Knowledge & .36 & 4.49 & & & & .000 & 1.23 \\
\hline & & $\begin{array}{l}\text { Symptom } \\
\text { Recognition }\end{array}$ & -.04 & -.49 & & & & .63 & 1.23 \\
\hline & \multirow{3}{*}{$\begin{array}{l}\text { QATT } \\
\text { Self- } \\
\text { perception } \\
\text { and } \\
\text { Patient- } \\
\text { Doctor }\end{array}$} & Model & & & .04 & .001 & .10 & .90 & \\
\hline & & Knowledge & .04 & .42 & & & & .67 & 1.23 \\
\hline & & $\begin{array}{l}\text { Symptom } \\
\text { Recognition }\end{array}$ & -.03 & -.31 & & & & .76 & 1.23 \\
\hline \multirow{3}{*}{$2 a$} & \multirow{3}{*}{$\begin{array}{l}\text { Time Spent } \\
\text { on Page }\end{array}$} & Model & & & .05 & .002 & .19 & .83 & \\
\hline & & $\begin{array}{l}\text { Misunderstanding } \\
\text { of ADHD }\end{array}$ & -.02 & -.29 & & & & .78 & 1.00 \\
\hline & & $\begin{array}{l}\text { Susceptibility to } \\
\text { ADHD Stigma }\end{array}$ & .04 & .54 & & & & .59 & 1.00 \\
\hline \multirow[b]{2}{*}{$2 b$} & \multirow{2}{*}{$\begin{array}{l}\text { Time Spent } \\
\text { on Page }\end{array}$} & Model & & & .16 & .03 & 2.26 & .11 & \\
\hline & & $\begin{array}{l}\text { Satisfaction with } \\
\text { Provider }\end{array}$ & -.12 & -1.19 & & & & .24 & 1.59 \\
\hline
\end{tabular}




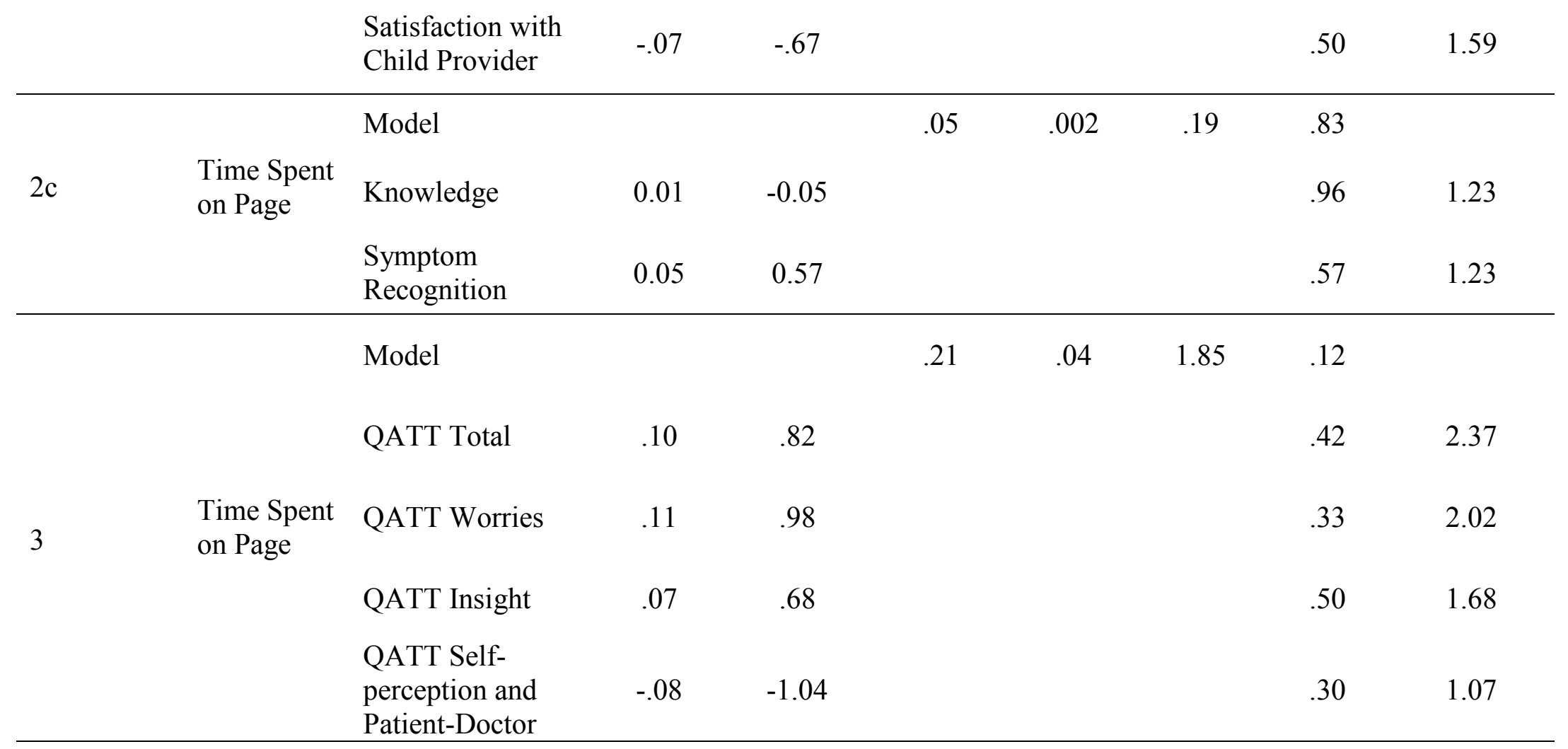

Note. QATT $=$ Questionnaire about Attitudes Towards

Treatment 
Table 5

Results of Logistic Regressions

\begin{tabular}{|c|c|c|c|c|c|c|c|}
\hline Hypothesis & $\begin{array}{l}\text { Dependent } \\
\text { Variable }\end{array}$ & $\beta$ & $S E$ & Wald $\chi^{2}$ & Nagelkerke $R^{2}$ & $p$ & $95 \% C I$ \\
\hline \multirow[t]{3}{*}{$2 \mathrm{a}$} & Model & & & & .004 & .83 & \\
\hline & $\begin{array}{l}\text { Misunderstanding } \\
\text { of ADHD }\end{array}$ & .12 & .25 & .25 & & .62 & $.69-1.86$ \\
\hline & $\begin{array}{l}\text { Susceptibility to } \\
\text { ADHD Stigma }\end{array}$ & -.08 & .24 & .12 & & .73 & $.58-1.47$ \\
\hline \multirow[t]{3}{*}{$2 b$} & Model & & & & .02 & .30 & \\
\hline & $\begin{array}{l}\text { Satisfaction with } \\
\text { Provider }\end{array}$ & -.17 & .39 & .18 & & .67 & $.39-1.83$ \\
\hline & $\begin{array}{l}\text { Satisfaction with } \\
\text { Child Provider }\end{array}$ & .48 & .34 & 2.04 & & .15 & $.83-3.12$ \\
\hline \multirow[t]{3}{*}{$2 \mathrm{c}$} & Model & & & & .01 & .44 & \\
\hline & Knowledge & -.03 & .10 & .09 & & .77 & $.81-1.17$ \\
\hline & $\begin{array}{l}\text { Symptom } \\
\text { Recognition }\end{array}$ & .39 & 0.3 & 1.64 & & .20 & $.82-2.66$ \\
\hline \multirow[t]{3}{*}{3} & Model & & & & .03 & .36 & \\
\hline & QATT Total & .05 & .04 & 1.66 & & .20 & $.98-1.13$ \\
\hline & QATT Worries & -.15 & .09 & 2.52 & & .11 & $.72-1.04$ \\
\hline
\end{tabular}




\begin{tabular}{lccccc} 
QATT Insight & -.01 & .07 & .01 & .91 & $.87-1.14$ \\
$\begin{array}{l}\text { QATT Self- } \\
\text { perception and }\end{array}$ & .11 & .11 & 1.02 & .31 & $.90-1.40$ \\
Patient-Doctor & & & & & \\
\hline
\end{tabular}

Note. QATT $=$ Questionnaire about Attitudes Towards Treatment 


\section{References}

Aase, H., \& Sagvolden, T. (2005). Moment-to-moment dynamics of ADHD behavior. Behavioral and Brain Functions, 1(1), 12. doi:10.1186/1744-9081-1-12

Ahmed, R., Borst, J., Wei, Y. C., \& Aslani, P. (2013). Parents' perspectives about factors influencing adherence to pharmacotherapy for ADHD. Journal of Attention Disorders, 1087054713499231. doi:10.1177/1087054713499231

Akinbami, L. J., Liu, X., Pastor, P. N., \& Reuben, C. A. (2011). Attention deficit hyperactivity disorder among children aged 5-17 years in the United States, 1998-2009. NCHS data brief, $70,1-8$.

Association, A. P. (2013). Diagnostic and statistical manual of mental disorders: DSM-5. Arlington, VA: American Psychiatric Publishing.

Barkley, R. A. (1997). Behavioral inhibition, sustained attention, and executive functions: constructing a unifying theory of ADHD. Psychol Bulletin, 121(1), 65-94.

Barkley, R. A. (2002). International Consensus Statement on ADHD. , 4l(12), 1389. doi:10.1097/00004583-200212000-00001

Barkley, R. A., Fischer, M., Smallish, L., \& Fletcher, K. (2006). Young adult outcome of hyperactive children: adaptive functioning in major life activities. Journal of the American Academy of Child and Adolescent Psychiatry, 45(2), 192-202.

Behrend, T. S., Sharek, D. J., Meade, A. W., \& Wiebe, E. N. (2011). The viability of crowdsourcing for survey research. Behaviorial Research Methods, 43(3), 800. doi:10.3758/s13428-011-0081-0 
Bennet, D. S., Power, T. J., Rostain, A. L., \& Carr, D. E. (1996). Parent acceptability and feasibility of ADHD interventions: assessment, correlates, and predictive validity. Journal of Pediatric Psychology, 21(5), 643-657.

Berger, I., Dor, T., Nevo, Y., \& Goldzweig, G. (2008). Attitudes toward attention-deficit hyperactivity disorder (ADHD) treatment: parents' and children's perspectives. Journal of Child Neurology, 23(9), 1036-1042 doi:10.1177/0883073808317726

Biederman, J., \& Faraone, S. V. (2002). Current concepts on the neurobiology of AttentionDeficit/Hyperactivity Disorder. Journal of Attention Disorders, 6, S7-S16.

Biederman, J., \& Faraone, S. V. (2005). Attention-deficit hyperactivity disorder. Lancet, 366, 237-246.

Biederman, J., Faraone, S. V., \& Monuteaux, M. C. (2002). Differential effect of environmental adversity by gender: Rutter's index of adversity in a group of boys and girls with and without ADHD. American Journal of Psychiatry, 159(9), 1556-1562. doi:doi.org/10.1176/appi.ajp.159.9.1556

Biederman, J., Faraone, S. V., Taylor, A., Sienna, M., Williamson, S., \& Fine, C. (1998a). Diagnostic continuity between child and adolescent ADHD: findings from a longitudinal clinical sample. Journal of the American Academy of Child and Adolescent Psychiatry, $37(3), 305-313$.

Biederman, J., Mick, E., \& Faraone, S. V. (1998b). Normalized functioning in youths with persistent ADHD. Journal of Pediatrics, 133, 544-551.

Biederman, J., Milberger, S., Faraone, S. V., Kiely, K., Guite, J., Mick, E., . . Reed, E. (1995). Family-environment risk factors for attention-deficit hyperactivity disorder: a test of Rutter's indicators of adversity. Archives of General Psychiatry, 52(6), 464-470. 
Biederman, J., Newcorn, J., \& Sprich, S. (1991). Comorbidity of attention deficit hyperactivity disorder with conduct, depressive, anxiety, and other disorders. American Journal of Psychiatry, 148(5), 564-577

Birnbaum, H. G., Kessler, R. C., Lowe, S. W., Secnik, K., Greenberg, P. E., Leong, S. A., \& Swensen, A. R. (2005). Costs of attention deficit-hyperactivity disorder (ADHD) in the US: excess costs of persons with ADHD and their family members in 2000. Current Medical Research and Opinion, 21(2), 195-206. doi:10.1185/030079904X20303.

Bögels, S., \& Phares, V. (2008). Fathers' role in the etiology, prevention and treatment of child anxiety: A review and new model. Clinical Psychology Review, 28(4), 539-558. doi:10.1016/j.cpr.2007.07.011

Brinkman, W. B., Majcher, J. H., Poling, L. M., Shi, G., Zender, M., Sucharew, H., ... Epstein, J. N. (2013). Shared decision-making to improve attention-deficit hyperactivity disorder care. Patient Education and Counseling, 93(1), 95-101. doi:10.1016/j.pec.2013.04.009

Brinkman, W. B., Sherman, S. N., Zmitrovich, A. R., Vissher, M. O., Crosby, L. E., Phelan, K. J., \& Donovan, E. F. (2009). Parental angst making and revisiting decisions about treatment of attention-deficit/hyperactivity disorder. Pediatrics, 124(2), 580-589. doi:10.1542/peds.2008-2569

Bronfenbrenner, U. (1994). Ecological models of human development. Readings on the development of children, 2, 37-43.

Buhrmester, M., Kwang, T., \& Gosling, S. D. (2011). Amazon's Mechanical Turk a new source of inexpensive, yet high-quality, data? Perspectives on Psychological Science, 6(1), 3-5. doi: $10.1177 / 1745691610393980$ 
Burns, J. A. (2013). Case Based Pediatrics for Medical Students and Residents (L Ed. 2 ed.). Hawaii: University of Hawaii.

Bussing, R., \& Gary, F. A. (2001). Practice guidelines and parental ADHD treatment evaluations: friends or foes? Harvard Review of Psychiatry, 9(5), 223-233. doi:10.1007/s00127-003-0674-8

Bussing, R., Koro-Ljungberg, M., Noguchi, K., Mason, D., Mayerson, G., \& Garvan, C. W. (2012). Willingness to use ADHD treatments: A mixed methods study of perceptions by adolescents, parents, health professionals, and teachers. Social Science \& Medicine, 74(1), 92-100. doi:10.1016/j.socscimed.2011.10.009

Bussing, R., Meyer, J., Zima, B. T., Mason, D. M., Gary, F. A., \& Garvan, C. W. (2015). Childhood ADHD symptoms: Association with parental social networks and mental health service us during adolescence. International Journal of Environmental Research and Public Health, 12(9), 11893-11909. doi:10.3390/ijerph120911893

Bussing, R., Zima, B. T., Gary, F. A., \& Garvan, C. W. (2003). Barriers to detection, helpseeking, and service use for children wit ADHD symptoms. The Journal of Behavioral Health Services and Research, 30(2), 176-189.

Carroll, A. E., Bauer, N. S., Dugan, T. M., Anand, V., Saha, C., \& Downs, S. M. (2013). Use of a computerized decision aid for ADHD diagnosis: a randomized controlled trial. Pediatrics, 132(3), e623-e629. doi:10.1542/peds.2013-0933

Co, P. T., Johnson, S. A., Poon, E. G., Fiskio, J., Rao, S. R., Van Cleave, J., . . Ferris, T. G. (2010). Electronic health record decision support and quality of care for children with ADHD. Pediatrics, 126(2), 239-246. 
Coles, M. E., Ravid, A., Gibb, B., George-Denn, D., Bronstein, L. R., \& McLeod, S. (2016). Adolescent mental health literacy: young people's knowledge of depression and social anxiety disorder. Journal of Adolescent Health, 58(1), 57-62. doi:10.1016/j.jadohealth.2015.09.017

Coletti, D. J., Pappadopulos, E., Katsiotas, N. J., Berest, A., Jensen, P. S., \& Kafantaris, V. (2012). Parent perspectives on the decision to initiate medication treatment of attentiondeficit/hyperactivity disorder. Journal of Child and Adolescent Psychopharmacology, 22(3), 226-237. doi:10.1089/cap.2011.0090

Corrigan, P. W. (2008). A toolkit for evaluating programs meant to erase the stigma of mental illness. IL: Illinois Institute of Technology.

Crano, W. D., \& Prislin, R. (2011). Attitudes and attitude change: Psychology Press.

Dakwar, E., Levin, F. R., Olfson, M., Wang, S., Kerridge, B., \& Blanco, C. (2014). First treatment contact for ADHD: Predictors of and gender differences in treatment seeking. Psychiatric Services, 65(12), 1465-1473. doi:10.1176/appi.ps.201300298

Davison, B. J., \& Degner, L. F. (1997). Empowerment of men newly diagnosed with prostate cancer. Cancer Nursing, 20(3), 187-196.

DosReis, S., Barksdale, C. L., Sherman, A., Maloney, K., \& Charach, A. (2010). Stigmatizing experiences of parents of children with a new diagnosis of ADHD. Psychiatric Services, 61(8), 811-816. doi:10.1176/appi.ps.61.8.811

Dougherty, D. D., Bonab, A. A., Spencer, T. J., Rauch, S. L., Madras, B. K., \& Fischman, A. J. (1999). Dopamine transporter density in patients with attention deficit hyperactivity disorder. Lancet, 354(9196), 2132-2133. doi:10.1016/S0140-6736(99)04030-1 
Dresel, S., Krause, J., Krause, K. H., LaFougere, C., Brinkbaumer, K., Kung, H. F., . . Tatsch, K. (2000). Attention deficit hyperactivity disorder: binding of [99mTc]TRODAT-1 to the dopamine transporter before and after methylphenidate treatment. European Journal of Nuclear Medicine, 27(10), 1518-1524.

DuPaul, G. J., Power, T., Anastopoulos, A. D., \& Reid, R. (2016). ADHD rating scale - 5 for children and adolescents: Checklists, norms, and clinical interpretations (5 ed.). New York, NY: The Guilford Press.

Epstein, J. N., Kelleher, K. J., Baum, R., Brinkman, W. B., Peugh, J., Gardner, W., . . Langberg, J. M. (2016). Impact of a Web-Portal Intervention on Community ADHD Care and Outcomes. Pediatrics. doi:10.1542/peds.2015-4240

Epstein, J. N., Langberg, J. M., Lichtenstein, P. K., Kolb, R., Altaye, M., \& Simon, J. O. (2011). Use of an Internet portal to improve community-based pediatric ADHD care: a cluster randomized trial. Pediatrics, 128(5), e1201-e1208. doi:10.1542/peds.2011-0872

Epstein, J. N., Langberg, J. M., Lichtenstein, P. K., Mainwaring, B. A., Luzader, C. P., \& Stark, L. J. (2008). Community-wide intervention to improve the attention-deficit/hyperactivity disorder assessment and treatment practices of community physicians. Pediatrics, 122(1), $19-27$.

Epstein, J. N., Rabiner, D., Johnson, D. E., FitzGerald, D. P., Chrisman, A., Erkanli, A., . . Norton, E. C. (2007). Improving attention-deficit/hyperactivity disorder treatment outcomes through use of a collaborative consultation treatment service by communitybased pediatricians: a cluster randomized trial. Archives of Pediatrics \& Adolescent Medicine, 161(9), 835-840. 
Fabiano, G. A., Pelham, J. W. E., Waschbusch, D. A., Gnagy, E. M., Lahey, B. B., Chronis, A. M., . . Burrows-MacLean, L. (2006). A practical measure of impairment: psychometric properties of the impairment rating scale in samples of children with attention deficit hyperactivity disorder and two school-based samples. Journal of Clinical Child and Adolescent Psychology, 35(3), 369-385. doi:10.1207/s15374424jccp3503_3

Faraone, S. V. (2003). Understanding the effect size of ADHD medications: implications for clinical care. Medscape Psychiatry and Mental Health, 8(2).

Faraone, S. V., \& Buitelaar, J. (2010). Comparing the efficacy of stimulants for ADHD in children and adolescents using meta-analysis. European Child \& Adolescent Psychiatry, 19(4), 353-364. doi:10.1007/s00787-009-0054-3

Ferrin, M., Ruiz-Veguilla, M., Blanc-Betes, M., Abd, S. E., Lax-Pericall, T., Sinclair, M., \& Taylor, E. (2012). Evaluation of attitudes towards treatment in adolescents with attention deficit hyperactivity disorder (ADHD). European Journal of Child and Adolescent Psychiatry, 21(7), 837-401. doi:10.1007/s00787-012-0277-6

Firmin, R. L., Luther, L., Lysaker, P. H., Minor, K. S., \& Salyers, M. P. (2016). Stigma resistance is positively associated with psychiatric and psychosocial outcomes: A metaanalysis. Schizophrenia Research, 175(1), 118-128. doi:10.1016/j.schres.2016.03.008

Florian, V., \& Elad, D. (1998). The Impact of Mothers' Sense of Empowerment oh the Metabolic Control of Their Children With Juvenile Diabetes. Journal of Pediatric Psychology, 23(4), 239-247.

Ford-Jones, P. C. (2015). Misdiagnosis of attention deficit hyperactivity disorder: 'Normal behaviour' and relative maturity. Paediatr Child Health, 20(4), 200-202. 
Geltman, P. L., Fried, L. E., Arsenault, L. N., Knowles, A. M., Link, D. A., Goldstein, J. N., . . . Hacker, K. A. (2015). A planned care approach and patient registry to improve adherence to clinical guidelines for the diagnosis and management of attention-deficit/hyperactivity disorder. Academic Pediatrics, 15(3), 289-296.

Goksoyr, P. K., \& Nottestad, J. A. (2008). The burden of untreated ADHD among adults: The role of stimulant medication. Addictive Behaviors, 33(2), 342-346.

doi:10.1016/j.addbeh.2007.09.008

Gulliver, A., Griffiths, K. M., \& Christensen, H. (2010). Perceived barriers and facilitators to mental health help-seeking in young people: A systematic review. BMC Psychiatry, 10(1), 113. doi:10.1186/1471-244X-10-113

Ha, J. F., \& Longnecker, N. (2010). Doctor-patient communication: a review. The Ochsner Journal, 10(1), 38-43.

Hansen, D. L., \& Hansen, E. H. (2006). Caught in a balancing act: Parents' dilemmas regarding their ADHD child's treatment with stimulant medication. Qualitative Health Research, 16(9), 1267-1285. doi:10.1177/1049732306292543

Heath, C. L., Curtis, D. F., Fan, W., \& McPherson, R. (2015). The association between parenting stress, parenting self-efficacy, and the clinical significance of child ADHD symptom change following behavior therapy. Child Psychiatry \& Human Development, 46(1), 118 129. doi:10.1007/s10578-014-0458-2

Hebert, J., Polotskaia, A., Joober, R., \& Grizenk, N. (2013). Adherence to psychostimulant medication in children with attention-deficit/hyperactivity disorder: the role of attitudes. Journal of the Canadian Academy of Child and Adolescent Psychiatry, 22(4), 317-323. 
Hoath, F. E., \& Sanders, M. R. (2002). A feasibility study of enhanced group triple P-positive parenting program for parents of children with attention-deficit/hyperactivity disorder. Behavior Change, 19, 191-206.

Hodgson, K., Hutchinson, A. D., \& Denson, L. (2014). Nonpharmacological treatments for ADHD: A meta-analytic review. Journal of Attention Disorders, 18(4), 275-282. doi: $10.1177 / 1087054712444732$

Hummelinck, A., \& Pollock, K. (2006). Parents' information needs about the treatment of their chronically ill child: a qualitative study. Patient Education and Counseling, 62(2), 228234. doi:10.1016/j.pec.2005.07.006

Jensen, P. S., Arnold, L. E., Swanson, J. M., Vitiello, B., Abikoff, H. B., Greenhill, L. L., . . Hur, K. (2007). 3-year follow-up of the NIMH MTA study. Journal of the American Academy of Child and Adolescent Psychiatry, 46(8), 989-1002.

Jiang, Y., Gurm, M., \& Johnston, C. (2014). Child impairment and parenting self-efficacy in relation to mothers' views of ADHD treatments. Journal of Attention Disorders, 18(6), 532-541. doi:10.1177/1087054712443412

Johnson, I. M., Siegel, J. T., \& Crano, W. D. (2014). Expanding the reach of vested interest in predicting attitude-consistent behavior. Social Influence, 9(1), 20-36. doi:10.1080/15534510.2012.738243

Johnston, C., Hommersen, P., \& Seipp, C. (2008). Acceptability of behavioral and pharmacological treatments for attention-deficit/hyperactivity disorder: relations to child and parent characteristics. Behavioral Therapy, 39(1), 22-32.

doi:10.1016/j.beth.2007.04.002 
Johnston, C., Mah, J. W., \& Regambal, M. (2010). Parenting cognitions and treatment beliefs as predictors of experience using behavioral parenting strategies in families of children with attention-deficit/hyperactivity disorder. Behavioral Therapy, 41(4), 491-504. doi:10.1016/j.beth.2010.02.001

Jorm, A. F., Christensen, H., \& Griffiths, K. M. (2006). The public's ability to recognize mental disorders and their beliefs about treatment: changes in Australia over 8 years. Australian and New Zealand Journal of Psychiatry, 40(1), 36-41. doi:10.1080/j.14401614.2006 .01738

Jorm, A. F., Wright, A., \& Morgan, A. J. (2007). Beliefs about appropriate first aid for young people with mental disorders: findings from an Australian national survey of youth and parents. Early Intervention in Psychiatry, 1(1), 61-70. doi:10.1111/j.17517893.2007.00012.x

Kazdin, A. E., Holland, L., \& Crowley, M. (1997). Family experience of barriers to treatment and premature termination from child therapy. Journal of Consulting and Clinical Psychology(65), 453-463. doi:doi:10.1037/0022-006X.65.3.453

Kellison, I., Bussing, R., Bell, L., \& Garvan, C. (2010). Assessment of stigma associated with attention-deficit hyperactivity disorder: Psychometric evaluation of the ADHD Stigma Questionnaire. Psychiatry Research, 178(2), 363-369. doi:

10.1016/j.psychres.2009.04.022

Kessler, R. C., Adler, L., Ames, M., Demler, O., Faraone, S., Hiripi, E., . . W Walters, E. E. (2005a). The World Health Organization Adult ADHD Self-Report Scale (ASRS): a short screening scale for use in the general population. Psychological Medicine, 35(2), 245256. 
Kessler, R. C., Berglund, P., Demler, O., Jin, R., Merikangas, K. R., \& Walters, E. (2005b). Lifetime prevalence and age-of-onset distributions of DSM-IV disorders in the National Comorbidity Survey Replication. Archives of General Psychiatry, 82(6), 593-602. doi:10.1001/archpsyc.62.6.593

Killeen, P. R., Tannock, R., \& Sagvolden, T. (2012). The four causes of ADHD: A framework. Behavioral Neuroscience of Attention Deficit Hyperactivity Disorder and Its Treatment, 9, $391-425$.

King, P. A. L., Cederbaum, J. A., Kurzban, S., Norton, T., Palmer, S. C., \& Coyne, J. C. (2015). Role of patient treatment beliefs and provider characteristics in establishing patientprovider relationships. Family Practice, 32(2), 224-231. doi:10.1093/fampra/cmu085

Kingery, J., Peneston, K. R., Rice, S. E., \& Wormuth, B. M. (2012). Parental anxious expectations and child anxiety predicting homesickness during overnight summer camp. Journal of Outdoor Recreation, Education, and Leadership, 4(3), 172-184. doi:doi.org/10.7768/1948-5123.1116

Kleim, B., Vauth, R., Adam, G., Stieglitz, R.-D., Hayward, P., \& Corrigan, P. (2008). Perceived stigma predicts low self-efficacy and poor coping in schizophrenia. Journal of Mental Health, 17(5), 482-491. doi:10.1080/09638230701506283

Klingberg, T., Fernell, E., Olesen, P. J., Johnson, M., Gustafsson, P., Dahlstrom, K., .. . Westerberg, H. (2005). Computerized training of working memory in children with ADHD-A randomized, controlled trial. Child and Adolescent Psychiatry, 44(2), 177-186. doi:10.1097/00004583-200502000-00010 
Kraetschmer, N., Sharpe, N., Urowitz, S., \& Deber, R. B. (2004). How does trust affect patient preferences for participation in decision - making? Health Expectations, 7(4), 317-326. doi:10.1111/j.1369-7625.2004.00296.x

Kroenke, K., Spitzer, R. L., Williams, J. B. W., \& Löwe, B. (2009). An ultra-brief screening scale for anxiety and depression: the PHQ-4. Psychosomatics, 50(6), 613-621. doi:10.1016/S0033-3182(09)70864-3

Lahey, B., Applegate, B., McBurnett, K., Biederman, J., Greenhill, L., Hynd, G. W., . . a al., e. (1994). DSM-IV field trials for attention deficit hyperactivity disorder in children and adolescents. American Journal of Psychiatry, 151(11), 1673-1675.

Lamb, M. E. (2004). The role of the father in child development: John Wiley \& Sons.

Lambek, R., Tannock, R., Dalsgaard, S., Trillingsgaard, A., Damm, D., \& Thomsen, P. H. (2011). Executive dysfunction in school-age children with ADHD. Journal of Attention Disorders, 15(8), 646-655. doi:10.1177/1087054710370935

Lavigne, J. V., Dulcan, M. K., LeBailly, S. A., Binns, H. J., Cummins, T. K., \& Jha, P. (2011). Computer-assisted management of attention-deficit/hyperactivity disorder. Pediatrics, 128(1), e46-e53. doi:10.1542/peds.2010-2684

Liu, C., Robin, A. L., Brenner, S., \& Eastman, J. (1991). Social acceptability of methylphenidate and behavior modification for treating attention deficit hyperactivity disorder. Pediatrics, $88(3), 560-565$

Martin, J. K., Pescosolido, B. A., \& Tuch, S. A. (2000). Of fear and loathing: the role of'disturbing behavior,'labels, and causal attributions in shaping public attitudes toward people with mental illness. Journal of Health and Social Behavior, 208-223. 
Martini, R., Hilt, R., Marx, L., Chenven, M., Naylor, M., Sarvet, B., \& Ptakowski, K. K. (2012). Best principles for integration of child psychiatry into the pediatric health home. Washington, DC: American Academy of Child \& Adolescent Psychiatry.

Miller, D. T., \& Prentice, D. A. (1996). The construction of social norms and standards Social psychology: Handbook of Basic Principles (pp. 799-829). New York, NY: Guildford Press.

Mojtabai, R., Olfson, M., Sampson, N. A., Jin, R., Druss, B., Wang, P. S., . . Kessler, R. C. (2011). Barriers to mental health treatment: Results from the National Comorbidity Survey Replication. Psychological Medicine, 41(8), 1751-1761. doi: $10.1017 / \mathrm{S} 0033291710002291$

Molina, B. S., Hinshaw, S. P., Swanson, J. M., Arnold, L. E., Vitiello, B., Jensen, P. S., . . . Group, M. T. A. C. (2009). The MTA at 8 years: prospective follow-up of children treated for combined-type ADHD in a multisite study. Journal of the American Academy of Child and Adolescent Psychiatry, 48(5), 484-500. doi:

10.1097/CHI.0b013e31819c23d0

Montgomery, D. C., Peck, E. A., \& Vining, G. G. (2001). Introduction to linear regression analysis (3 ed.). New York, NY: John Wiley \& Sons.

Mukolo, A., \& Heflinger, C. A. (2011). Factors associated with attributions about child health conditions and social distance preference. Community Mental Health Journal, 47(3), 286299. doi: 10.1007/s 10597-010-9325-1

Nigg, J. T., Nikolas, M., Knottnerus, G. M., Cavanagh, K., \& Friderici, K. (2010). Confirmation and extension of association of blood lead with attention - deficit/hyperactivity disorder (ADHD) and ADHD symptom domains at population - typical exposure levels. Journal 
of Child Psychology and Psychiatry, 51(1), 58-65. doi:10.1111/j.14697610.2009.02135.x

Norvilitis, J. M., Scime, M., \& Lee, J. S. (2002). Courtesy stigma in mothers of children with attention-deficit/hyperactivity disorder: A preliminary investiation. Journal of Attention Disorders, 6(2), 61-68.

O’Driscoll, C., Heary, C., Hennessy, E., \& McKeague, L. (2012). Explicit and implicit stigma towards peers with mental health problems in childhood and adolescence. Journal of Child Psychology and Psychiatry, 53(10), 1054-1062. doi:10.1111/j.14697610.2012.02580.x

Ohan, J. L., Visser, T. A. W., Moss, R. G., \& Allen, N. (2013). Parents' stigmatizing attitudes toward psychiatric labels for ADHD and depression. Psychiatric Services, 64(12), 12701273.

Olson, B. G., Rosenbaum, P. F., Dosa, N. P., \& Roizen, N. J. (2005). Improving guideline adherence for the diagnosis of ADHD in an ambulatory pediatric setting. Ambulatory Pediatrics, 5(3), 138-142.

Osborne, J. (2005). Notes on the use of data transformations. Practical Assessment, Research and Evaluation, 9(1), 42-50.

Partridge, B., Lucke, J., \& Hall, W. (2012). Public attitudes towards the acceptability of using drugs to treat depression and ADHD. Australia and New Zealand Journal of Psychiatry, 46(10), 958-965. doi:10.1177/0004867412450755

Partridge, B., Lucke, J., \& Hall, W. (2014). Over-diagnosed and over-treated: a survey of Australian public attitudes towards the acceptability of drug treatment for depression and ADHD. BMC Psychiatry, 14, 74. doi:10.1186/1471-244X-14-74 
Pelham, J. W. E., Fabiano, G. A., Waxmonsky, J. G., Greiner, A. R., Gnagy, E. M., Pelham III, W. E., . . Hart, K. (2016). Treatment sequencing for childhood ADHD: A multiplerandomization study of adaptive medication and behavioral interventions. Journal of Clinical Child \& Adolescent Psychology, 45(4), 396-415. doi:

$10.1080 / 15374416.2015 .1105138$

Perkins, D. D., \& Zimmerman, M. A. (1995). Empowerment theory, research, and application. American Journal of Community Psychology, 23(5), 569-579 doi: 0091-0627/95/1000$0569507.50 /$

Perry, Y., Petrie, K., Buckley, H., Cavanagh, L., Clarke, D., Winslade, M., . . Christensen, H. (2014). Effects of a classroom-based educational resource on adolescent mental health literacy: a cluster randomised controlled trial. Journal of Adolescence, 37(7), 1143-1151. doi:10.1016/j.adolescence.2014.08.001

Pescosolido, B. A., Fettes, D., Martin, J. K., Monahan, J., \& McLeod, J. D. (2007). Perceived dangerousness of children with mental health problems and support for coerced treatment. Psychiatric Services, 58(5), 619-625.

Pescosolido, B. A., Jensen, P. S., Martin, J. K., Perry, B. L., Olafsdottir, S., \& Fettes, D. (2008). Public knowledge and assessment of child mental health problems: Findings from the National Stigma Study-Children. Journal of American Academy of Child and Adolescent Psychiatry, 47(3), 339-349. doi:10.1097/CHI.0b013e318160e3a0

Phares, V., Fields, S., Kamboukos, D., \& Lopez, E. X. (2005a). Still looking for Poppa. American Psychological Association, 735-736. 
Phares, V., Lopez, E., Fields, S., Kamboukos, D., \& Duhig, A. M. (2005b). Are fathers involved in pediatric psychology research and treatment? Journal of Pediatric Psychology, 30(8), 631-643. doi:10.1093/jpepsy/jsi050

Pinfold, V., Toulmin, H., Thornicroft, G., Huxley, P., Farmer, P., \& Graham, T. (2003).

Reducing psychiatric stigma and discrimination: evaluation of educational interventions in UK secondary schools. The British Journal of Psychiatry, 182(4), 342-346. doi:10.1192/bjp.182.4.342

Pinto, M. D., Hickman, R., Logsdon, M. C., \& Burant, C. (2012). Psychometric evaluation of the revised attribution questionnaire (r-AQ) to measure mental illness stigma in adolescents. Journal of Nursing Measurement, 20(1), 47-58.

Pliszka, S. (2007). Practice parameter for the assessment and treatment of children and adolescents with attention-deficit/hyperactivity disorder. Journal of the American Academy of Child and Adolescent Psychiatry, 46(7), 894-921.

Powers, R. L., Marks, D. J., Miller, C. J., Newcorn, J. H., \& Halperin, J. M. (2008). Stimulant treatment in children with attention-deficit/hyperactivity disorder moderates adolescent academic outcome. Journal of Child and Adolescent Psychopharmacology, 18(5), 449459. doi:10.1089/cap.2008.021

Prochaska, J. O., \& Velicer, W. F. (1997). The transtheoretical model of health behavior change. American journal of health promotion, 12(1), 38-48.

Ramos-Quiroga, J. A., \& Casas, M. (2011). Achieving remission as a routine goal of pharmacotherapy in attention-deficit hyperactivity disorder. CNS Drugs, 25(1), 17-36. 
Rosenstock, I. M. (1990). The health belief model: Explaining health behavior through expectancies. Health Behavior and Health Education: Theory, Research, and Practice., $39-62$.

Ryan, R. M., \& Deci, E. L. (2000). Self-determination theory and the facilitation of intrinsic motivation, social development, and well-being. American Psychologist, 55(1), 68-78. doi: 10.1037110003-066X.55.1.68

Ryan, R. M., Kuhl, J., \& Deci, E. L. (1997). Nature and autonomy: An organizational view of social and neurobiological aspects of self-regulation in behavior and development. Development and Psychopathology, 9(4), 701-728

Sage, A., Carpenter, D., Sayner, R., Thomas, K., Mann, L., Sulzer, S., . . Sleath, B. (2017). Online Information-Seeking Behaviors of Parents of Children With ADHD. Clinical Pediatrics. doi:10.1177/0009922817691821

Sayal, K., Goodman, R., \& Ford, T. (2006). Barriers to the identification of children with attention deficit/hyperactivity disorder. Journal of Child Psychology and Psychiatry, 47(7), 744-750. doi:10.1111/j.1469-7610.2005.01553.x

Scassellati, C., Bonvicini, C., Faraone, S. V., \& Gennarelli, M. (2012). Biomarkers and attentiondeficit/hyperactivity disorder: a systematic review and meta-analyses. Journal of the American Academy of Child and Adolescent Psychiatry, 51(10), 1003-1019 e1020. doi:10.1016/j.jaac.2012.08.015

Schachter, H. M., Girardi, A., Ly, M., Lacroix, D., Lumb, A. B., van Berkom, J., \& Gill, R. (2008). Effects of school-based interventions on mental health stigmatization: a systematic review. Child and Adolescent Psychiatry and Mental Health, 2(1), 18 doi:10.1186/1753-2000-2-18 
Schipper, E. d., Lundequist, A., Wilteus, A. L., Coghill, D., Vries, P. J. d., Granlund, M., .. . Bolte, S. (2015). A comprehensive scoping review of ability and disability in ADHD using the International Clssification of Functioning, Disability, and Health-Children and Youth Version (ICF-CY). European Child and Adolscent Psychiatry, 24, 859-871. doi:10.1007/s00787-015-0727-z

Schultz, B. K., Evans, S. W., \& Serpell, Z. N. (2009). Preventing failure among middle school students with attention deficit hyperactivity disorder: A survival analysis. School Psychology Review, 38(1), 14-27.

Schwarz, A. (2013, February 2, 2013). Drowned in a sea of prescriptions. New York Times.

Sciberras, E., Iyer, S., Efron, D., \& Green, J. (2010). Information needs of parents of children with attention-deficit/hyperactivity disorder. Clinical Pediatrics, 49(2), 150-157.

Sciutto, M. J. (2015). ADHD knowledge, misconceptions, and treatment acceptability. Journal of Attention Disorders, 19(2), 91-98. doi:10.1177/1087054713493316.

Sergeant, J. A. (2005). Modeling attention-deficit/hperactivity diorder: A critical appraisal of the cognitive-energetic model. Biological Psychiatry, 57, 1248-1255.

Shapiro, D. N., Chandler, J., \& Mueller, P. A. (2013). Using Mechanical Turk to study clinical populations. Clinical Psychological Science, 1(2), 213-220.

doi:10.1177/2167702612469015

Shaw, M., Hodgkins, P., Caci, H., Young, S., Kahle, J., Woods, A. G., \& Arnold, L. E. (2012). A systematic review and analysis of long-term outcomes in attention deficit hyperactivity disorder: Effects of treatment and non-treatment. BMC Medicine, 10(1), 99-1123. doi:10.1186/1741-7015-10-99 
Sheeran, P. (2002). Intention-behavior relations: A conceptual and empirical review. European Review of Social Psychology, 12(1), 1-36. doi:10.1080/14792772143000003

Sonuga-Barke, E. J. (2002). Psychological heterogeneity in AD/HD--a dual pathway model of behaviour and cognition. Behavavioral Brain Research, 130(1-2), 29-36.

Sonuga-Barke, E. J., Brandeis, D., Cortese, S., Daley, D., Ferrin, M., Holtmann, M., .. .

Sergeant, J. (2013). Nonpharmacological interventions for ADHD: systematic review and meta-analyses of randomized controlled trials of dietary and psychological treatments. American Journal of Psychiatry, 170(3), 275-289. doi:10.1176/appi.ajp.2012.12070991

Spence, S., Burns, J., Boucher, S., Glover, S., Graetz, B., Kay, D., . . Sawyer, M. (2005). The beyondblue Schools Research Initiative: conceptual framework and intervention. Australasian Psychiatry, 13(2), 159-164.

Spencer, T. J., Biederman, J., \& Mick, E. (2007). Attention-Deficity/Hyperactivity Disorder: Diagnosis, lifespan, comorbidities, and neurobiology. Journal of Pediatric Psychology, 32(6), 631-642. doi:10.1093/jpepsy/jsm005

Stewart, J. L., Pyke-Grimm, K. A., \& Kelly, K. P. (2005). Parental treatment decision making in pediatric oncology. Seminars in Oncology Nursing, 21(2), 89-97.

Stiffman, A. R., Pescosolido, B., \& Cabassa, L. J. (2004). Building a model to understand youth service access: The gateway provider model. Mental Health Services Research, 6(4), 189-198. doi:1522-3434/04/1200-0189/0

Stroh, J., Frankenberger, W., Wood, C., \& Pahl, S. (2008). The use of stimulant medication and behavioral interventions for the treatment of attention deficit hyperactivity disorder: A survey of parents' knowledge, attitudes, and experiences. Journal of Child and Family Studies, 17(3), 385-401. doi:10.1007/s10826-007-9149-y 
Subcommittee on Attention-Deficit/Hyperactivity, D., Steering Committee on Quality, I., Management, Wolraich, M., Brown, L., Brown, R. T., . . Visser, S. (2011). ADHD: clinical practice guideline for the diagnosis, evaluation, and treatment of attentiondeficit/hyperactivity disorder in children and adolescents. Pediatrics, 128(5), 1007-1022. doi:10.1542/peds.2011-2654

Suzuki, S., Holloway, S. D., Yamamoto, Y., \& Mindnich, J. D. (2009). Parenting self-efficacy and social support in Japan and the United States. Journal of Family Issues, 30(11), 1505-1526. doi:10.1177/0192513X09336830

Swanson, J. M., \& Volkow, N. D. (2002). Pharmacokinetic and pharmacodynamic properties of stimulants: implications for the design of new treatments for ADHD. Behavaioral Brain Research, 130(1-2), 73-78.

Tabachnick, B. G., \& Fidell, L. S. (2007). Using Multivariate Statistics, 5th Edn Boston: Pearson Education.

Taylor, L. E., Ponzini, G., \& Schofield, C. A. (Unpublished Manuscript). Increasing Knowledge and Decreasing Stigma for Mental Illness: An Open Trial in Adolescents.

Tudge, J. R. H., Mokrova, I., Hatfield, B. E., \& Karnik, R. B. (2009). Uses and misuses of Bronfenbrenner's bioecological theory of human development. Journal of Family Theory \& Review, 1(4), 198-210

Vermeire, E., Hearnshaw, H., Van Royen, P., \& Denekens, J. (2001). Patient adherence to treatment: Three decades of research. A comprehensive review. Journal of Clinical Pharmacy and Therapeutics, 26(5), 331-342

Visser, S. N., Danielson, M. L., Bitsko, R. H., Holbrook, J. R., Kogan, M. D., Ghandour, R. M., . . . Blumberg, S. J. (2014). Trends in the parent-report of health care provider-diagnosed 
and medicated attention-deficit/hyperactivity disorder: United States, 2003-2011. Journal of the American Academy of Child and Adolescent Psychiatry, 53(1), 34-46 e32. doi:10.1016/j.jaac.2013.09.001

von Rhein, D., Mennes, M., van Ewijk, H., Groenman, A. P., Zwiers, M. P., Oosterlaan, J., . . . Buitelaar, J. (2015). The NeuroIMAGE study: A prospective phenotypic, cognitive, genetic and MRI study in children with attention-deficit/hyperactivity disorder. Design and descriptives. European Child and Adolescent Psychiatry, 24(3), 265-281. doi:10.1007/s00787-014-0573-4

Wåhlstedt, C., Thorell, L. B., \& Bohlin, G. (2009). Heterogeneity in ADHD: Neuropsychological pathways, comorbidity and symptom domains. Journal of Abnormal Child Psychology, 37(4), 551-564. doi:10.1007/s10802-008-9286-9

Wang, P. S., Berglund, P., Olfson, M., Pincus, H. A., Wells, K. B., \& Kessler, R. C. (2005). Failure and delay in initial treatment contact after first onset of mental disorders in the national comorbidity survey replication. JAMA Psychiatry, 62(6), 603-613. doi:10.1001/archpsyc.62.6.603

Watson, A. C., Otey, E., Westbrook, A. L., Gardner, A. L., Lamb, T. A., Corrigan, P. W., \& Fenton, W. S. (2004). Changing middle schoolers' attitudes about mental illness through education. Schizophrenia Bulletin, 30(3), 563-572.

West, S. G., Finch, J. F., \& Curran, P. J. (1995). Structural equation models with nonnormal variables: Problems and remedies.

Whalen, C. K., Jamner, L. D., Henker, B., Gehricke, J.-G., \& King, P. S. (2003). Is there a link between adolescent cigarette smoking and pharmacotherapy for ADHD? Psychology of Addictive Behaviors, 17(4), 332-335. doi: 10.1037/0893-164X.17.4.332 
Wilens, T. E., Biederman, J., \& Spencer, T. J. (2002). Attention deficit/hyperactivity disorder across the lifespan. Annual Review of Medicine, 53(1), 113-131. doi:10.1146/annurev.med.53.082901.103945

Wilens, T. E., Faraone, S. V., Biederman, J., \& Gunawardene, S. (2003). Does stimulant therapy of attention deficit hyperactivity disorder beget later substance abuse? Pediatrics, 111, 179-185.

Willcutt, E. G., Doyle, A. E., Nigg, J. T., Faraone, S. V., \& Pennington, B. F. (2005). Validity of the executive function theory of attention-deficit/hyperactivity disorder: a meta-analytic review. Biological Psychiatry, 57(11), 1336-1346. doi:10.1016/j.biopsych.2005.02.006

Wyn, J., Cahill, H., Holdsworth, R., Rowling, L., \& Carson, S. (2000). MindMatters, a wholeschool approach promoting mental health and wellbeing. Australian \& New Zealand Journal of Psychiatry, 34(4), 594-601. 


\section{Lea E. Taylor Vita}

\section{Contact:}

313 Huntington Hall

Syracuse, NY 13244

\section{Education:}

Syracuse University

Department of Psychology, Clinical Psychology Ph.D. Program

Skidmore College

Department of Psychology, Bachelors of Arts
2015 - current

$2011-2015$ 